\title{
A new type of experimentally proposed in situ heat/gas clean foam fracturing fluid system
}

\author{
Kuangsheng Zhang ${ }^{1} \cdot$ Zhenfeng Zhao $^{1} \cdot$ Meirong Tang ${ }^{1} \cdot$ Wenbin Chen ${ }^{1} \cdot$ Chengwang Wang $^{1} \cdot$ Xinyu Mao $^{2}$. \\ Nianyin $\mathrm{Li}^{2}$ (B)
}

Received: 1 May 2020 / Accepted: 9 August 2020 / Published online: 18 August 2020

(c) The Author(s) 2020

\begin{abstract}
When cold fluid is injected into low-temperature, low-pressure, low-permeability reservoirs containing wax-bearing heavy oil, cryogenic paraffin deposition and heavy oil condensation will occur, thus damaging the formation. Moreover, the formation pressure coefficient is low and the working fluid flowback efficiency is low, which affects the fracturing stimulation effect. Therefore, an in situ heat/gas clean foam fracturing fluid system is proposed. This system can ensure that conventional fracturing fluid can create fractures and carry proppant in the reservoir, generate heat in situ to avoid cold damage, reduce the viscosity, and improve the fluidity of crude oil. The in situ heat fracturing fluid generates a large amount of inert gas while generating heat, thus forming foam-like fracturing fluid, reducing fluid loss, improving proppant-carrying performance, improving gel-breaking performance, effectively improving crack conductivity, and is clean and environmentally friendly. Based on the improved existing fracturing fluid system, in this paper, a new type of in situ heat fracturing fluid system is proposed, and a system optimization evaluation is conducted through laboratory experiments according to the performance evaluation standard of water-based fracturing fluid. Compared with the traditional in situ heat fracturing fluid system, the fracturing fluid system proposed in this study generates a large amount of inert gas and form foam-like fracturing fluid, reduces fluid loss, enhances the proppant-carrying capacity and gel-breaking performance, improves crack conductivity, the gel without residue and that the gel-breaking liquid is clean and harmless.
\end{abstract}

Keywords In situ heat/gas clean foam fracturing fluid system $\cdot$ Paraffin deposition $\cdot$ Heavy oil $\cdot$ Proppant-carrying capacity $\cdot$ Gel-breaking capacity

\section{Introduction}

Fracturing stimulation can effectively transform low-pressure, low-permeability reservoirs, and increase productivity. It has become one of the main measures to stabilize and increase production in oil fields. At present, the most widely used fracturing fluid is water-based fracturing fluid. Conventional water-based fracturing fluid is suitable for most reservoirs, but it cannot achieve the ideal fracturing effect for low-temperature reservoirs that contain heavy oil. The

Nianyin Li

lnyswpu@163.com

$1 \quad$ Petroleum Technology Research Institute, Petrochina Changqing Oilfield Company, Xi' an, Shaanxi, China

2 State Key Laboratory of Oil and Gas Reservoir Geology and Exploitation Engineering, Southwest Petroleum University, Chengdu, Sichuan, China primary reason for this is that cold fluid injection leads to cryogenic paraffin deposition and heavy oil condensation, which reduces the permeability of fractures. The proposal of the in situ heat fracturing fluid system is based on the fracturing transformation of low-temperature, low-pressure, low-permeability reservoirs containing wax-bearing heavy oil (Shaoul et al. 2009; Goenka et al. 2014). This system reduces the cold damage through the addition of heat-generating agents to the fracturing fluid to increase the temperature of the system (Tiwari et al. 2014; Collesi et al. 1987; McSpadden et al. 1986; Ashton et al. 1989). After the in situ heat fracturing fluid system is pumped into the formation, heat-generating agents can react to produce large amounts of heat and inert gas (Rollins and Taylor 1959; Al-Taq et al., 2014). The system forms a foam-like fracturing fluid, which effectively reduces fluid loss, increases pressure, and promotes flowback (Saidu Mohamed 2013; Mitchell et al. 1984; Khalil and de Franco 1990). However, the heat-generating 
agents are reacted based on an acidic environment (Bayless 1997; Bayless 1998, 2000), but the conventional water-based fracturing fluid system is crosslinked and carries proppant in a slightly alkaline environment. Therefore, it is necessary to use a new type of acid-resistant fracturing fluid system in combination with a heat-generating agent system (Davies et al. 1981).

Currently, common in situ heat fracturing fluid systems include a modified guar gum in situ heat fracturing fluid system, an in situ heat capsule fracturing fluid system, and an in situ heat foam fracturing fluid system. The modified guar gum in situ heat fracturing fluid system achieves crosslinking in an acidic environment through the modification of guar gum. The system mixes proppant on the ground and crosslinks to carry the proppant into the formation. However, the ability of this system to carry proppant is not ideal, and it contains a large amount of gel-breaking residue, which can easily damage the reservoir (Khade and Shah 2003). The in situ heat capsule fracturing fluid system wraps gel breakers and an in situ heat reaction catalyst in the capsule. During the fracturing construction, the gel breaker does not directly contact the crosslinked gel, so the viscosity of the gel can be prevented from prematurely decreasing without affecting the system's ability to produce cracks and carry proppant (Burgos et al. 2004). In the late stage of fracturing construction, the capsule releases the gel breaker and the heat-generating reaction catalyst, which results in an increase in the formation temperature and generates a large quantity of inert gas. As a result, breaking and hydration are maximized and that leads to the good performance of fracturing fluid breaking and backflow, reducing formation damage, and promoting the recovery of reservoirs containing wax-bearing heavy oil. However, this system is expensive to construct and has low economic gains. The in situ heat foam fracturing fluid system can crosslink and carry proppant in an acidic environment. Its functions include automatic temperature increase, automatic pressure increase, in situ foaming, automatic density reduction, and automatic gas lift, and it has good system performance (Bullen 1980; Harris 1985; Harris and Heath 1996; Blauer and Kohlhaas 1974; Farajzadeh et al., 2009). However, the breaking of the system is difficult and can easily damage the reservoir (Moorhouse et al. 1998).

In this paper, using $\mathrm{XX}$ reservoir of $\mathrm{XX}$ oilfield as an example, the main factors affecting the performance of in situ heat fracturing fluid are analyzed and optimized through laboratory experiments. According to the results, a new type of in situ heat/gas clean foam fracturing fluid system is prepared, and its performance is evaluated. Based on the system characteristics of in situ heat/gas clean foam fracturing fluid, a supporting fracturing process is provided for on-site construction and application. The experimental results show that the in situ heat fracturing fluid system can
Table 1 Temperature and pressure characteristics of XX reservoir in XX oil field

\begin{tabular}{cllll}
\hline Region & $\begin{array}{l}\text { Reservoir } \\
\text { pressure } \\
(\mathrm{MPa})\end{array}$ & $\begin{array}{l}\text { Reservoir } \\
\text { temperature } \\
\left({ }^{\circ} \mathrm{C}\right)\end{array}$ & $\begin{array}{l}\text { Saturation } \\
\text { pressure } \\
(\mathrm{MPa})\end{array}$ & $\begin{array}{l}\text { Gas-oil } \\
\text { ratio } \\
\left(\mathrm{m}^{3} / \mathrm{t}\right)\end{array}$ \\
\hline $\begin{array}{c}\text { Western } \\
\text { region }\end{array}$ & 16.39 & 61.19 & 8.12 & 72.6 \\
$\begin{array}{c}\text { Eastern } \\
\text { region }\end{array}$ & 17.69 & 67.3 & 8.25 & 78.1 \\
\hline
\end{tabular}

Table 2 Comparison of C8 layer fluid properties in Wells 19, 20, and Z

\begin{tabular}{llllll}
\hline $\begin{array}{l}\text { Well } \\
\text { number }\end{array}$ & Layer & $\begin{array}{l}\text { Density }(\mathrm{g} / \\
\left.\mathrm{m}^{3}\right)\end{array}$ & $\begin{array}{l}\text { Viscosity } \\
(\mathrm{Pa} \mathrm{s})\end{array}$ & $\begin{array}{l}\text { Initial boil- } \\
\text { ing point } \\
\left({ }^{\circ} \mathrm{C}\right)\end{array}$ & $\begin{array}{l}\text { Freezing } \\
\text { point } \\
\left({ }^{\circ} \mathrm{C}\right)\end{array}$ \\
\hline 19 & $\mathrm{C} 8$ & 0.94 & 23.2 & 166 & 22 \\
20 & $\mathrm{C} 8$ & 0.88 & 29.6 & 130 & 14.3 \\
$\mathrm{Z}$ & $\mathrm{C} 8$ & 0.75 & 6.0 & 74.2 & 20 \\
\hline
\end{tabular}

effectively avoid the problem of cold damage to the working fluid, increase production, and effectively crosslink and carry proppant in an acidic environment. The gel-breaking performance of the system is good, the gel-breaking liquid is clear, does not contain residue, is clean and environmentally friendly, and causes minimal damage.

\section{Performance evaluation and optimization of in situ heat system}

\section{Geological characteristics of low-pressure reservoirs containing wax-bearing heavy oil in XX oilfield}

The temperature and pressure characteristics of the XX reservoir in the XX oilfield are shown in Table 1. The reservoir temperature is $61-67{ }^{\circ} \mathrm{C}$, and the formation pressure coefficient is low (0.8). The fluids in the C8 layer of wells 19 and 20 were selected for analysis. As shown in Table 2, the crude oil of this reservoir has a higher density, higher viscosity (above $20 \mathrm{~Pa} \mathrm{~s}$ at $50{ }^{\circ} \mathrm{C}$ ), and a lower freezing point than conventional crude oil. The test results of the laboratory crude oil viscosity-temperature curve are shown in Fig. 1. When the temperature is less than $30^{\circ} \mathrm{C}$, crude oil easily solidifies, and its fluidity is poor. According to the temperature, pressure, and crude oil test results of the reservoir, the reservoir has typical low-pressure and high-condensation characteristics (Tuttle 1983).

High-condensate oil is characterized by a high freezing point (typically $40-67{ }^{\circ} \mathrm{C}$, with a maximum of $69{ }^{\circ} \mathrm{C}$ ) and high wax content (typically $30-35 \%$, with a maximum of $45 \%)$. When the conventional hydraulic fracturing operation 


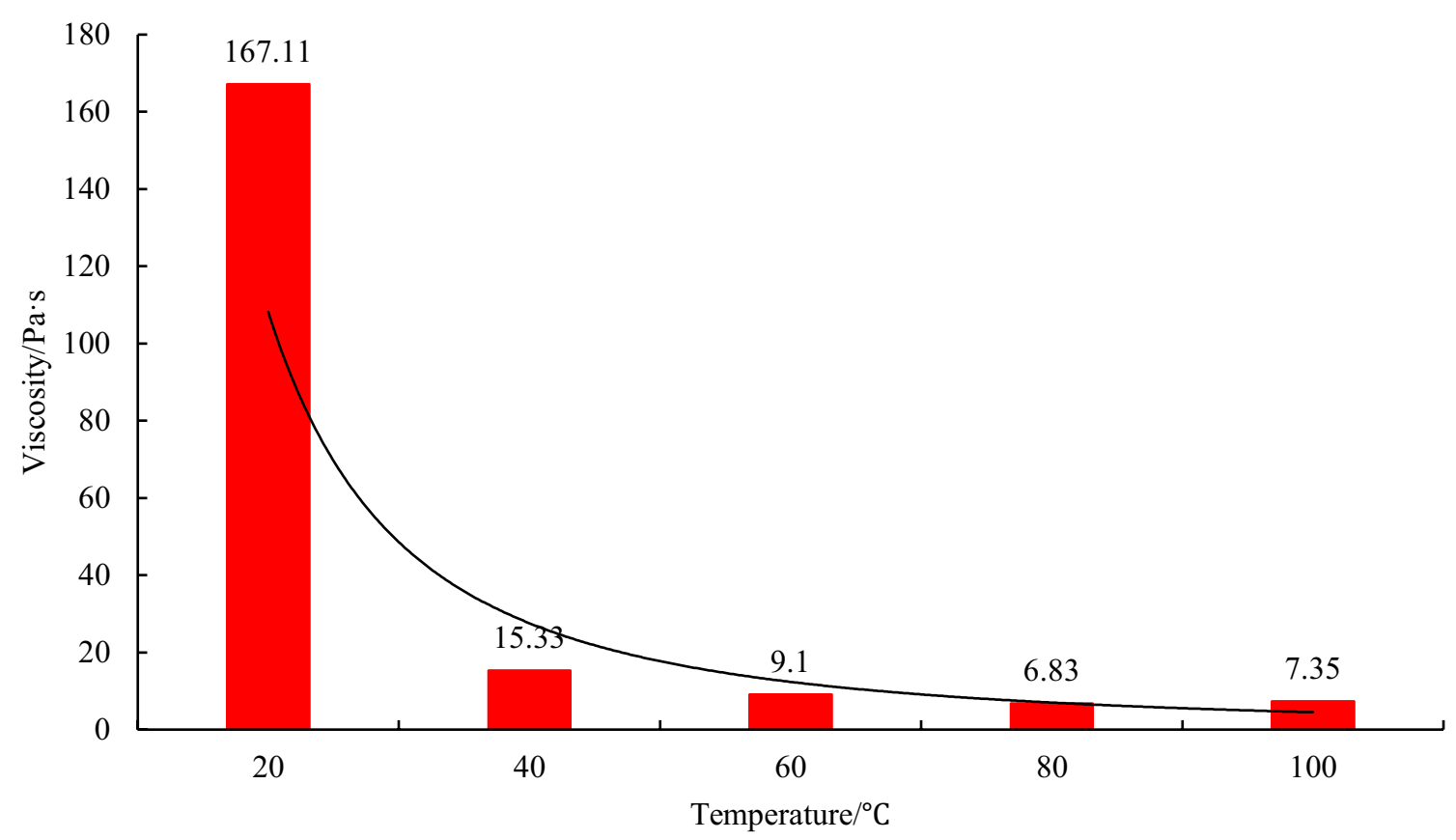

Fig. 1 Viscosity-temperature curve of crude oil test in Well 19

is adopted, the cold fluid injected into the formation will cool the crude oil around the bottom of the well, causing the crude oil to increase in viscosity, precipitate wax, or solidify, thus blocking part of the flow channel. Paraffin, colloid, asphalt, etc., contained in crude oil, will precipitate out when the ambient temperature decreases, causing organic matter to plug, which incurs cold damage to the reservoir and thus reduces the permeability of the fracture. Therefore, a solution to the problem of fracturing fluid cold damage to reservoirs containing wax-bearing heavy oil is the key to improving the constriction effect of low-temperature reservoirs containing wax-bearing heavy oil.

A new type of in situ heat/gas clean foam fracturing fluid system is proposed based on low-pressure, low-temperature reservoirs containing wax-bearing heavy oil. The system should have good rheological, sand-carrying and gel-breaking properties; be clean and harmless; be able to adapt to low-temperature, low-pressure, low-permeability, and highcondensate reservoirs; and effectively prevent cold damage. The in situ heat fracturing fluid system was designed based on the characteristics of the XX reservoir in the XX oilfield, and the formation was required to heat to above $50{ }^{\circ} \mathrm{C}$ and increase to $60 \%$ of the final temperature within $10 \mathrm{~min}$.

\section{Performance evaluation and optimization of in situ heat system}

\section{Peak temperature}

The peak temperature is the highest temperature the in situ heat system can reach, which directly determines the heating performance of the in situ system. Therefore, to optimize the in situ heat system and ensure the best overall performance, laboratory experiments were conducted at the heat-generating system's peak temperature using different concentrations of heat-generating agent $\mathrm{A}$ and heat-generating agent $\mathrm{B} .{ }^{1}$

The temperature rise performance evaluation experiment was carried out at room temperature $\left(20^{\circ} \mathrm{C}\right)$, using different concentrations of heat-generating agents $\mathrm{A}$ and B. Five control groups with a concentration gradient of $0.5 \mathrm{~mol} / \mathrm{L}$ and a concentration range of $1-3 \mathrm{~mol} / \mathrm{L}$ were set. $2 \% 1$ \# catalyst $^{2}$ was selected for the in situ heat system with heat-generating agents $\mathrm{A}$ and $\mathrm{B}$. The total volume of each group of solutions was $100 \mathrm{~mL}$; temperature measurement experiments were carried out in self-made sealed thermal

\footnotetext{
1 The heat-generating agent $\mathrm{A}$ and the heat-generating agent $\mathrm{B}$ are exothermic reactants, the reaction enthalpy conforms to actual production needs and the safety risks are small.

2 Among the several catalysts of the heat-generating system, 1\# catalyst is the one with the best heat-generating efficiency.
} 


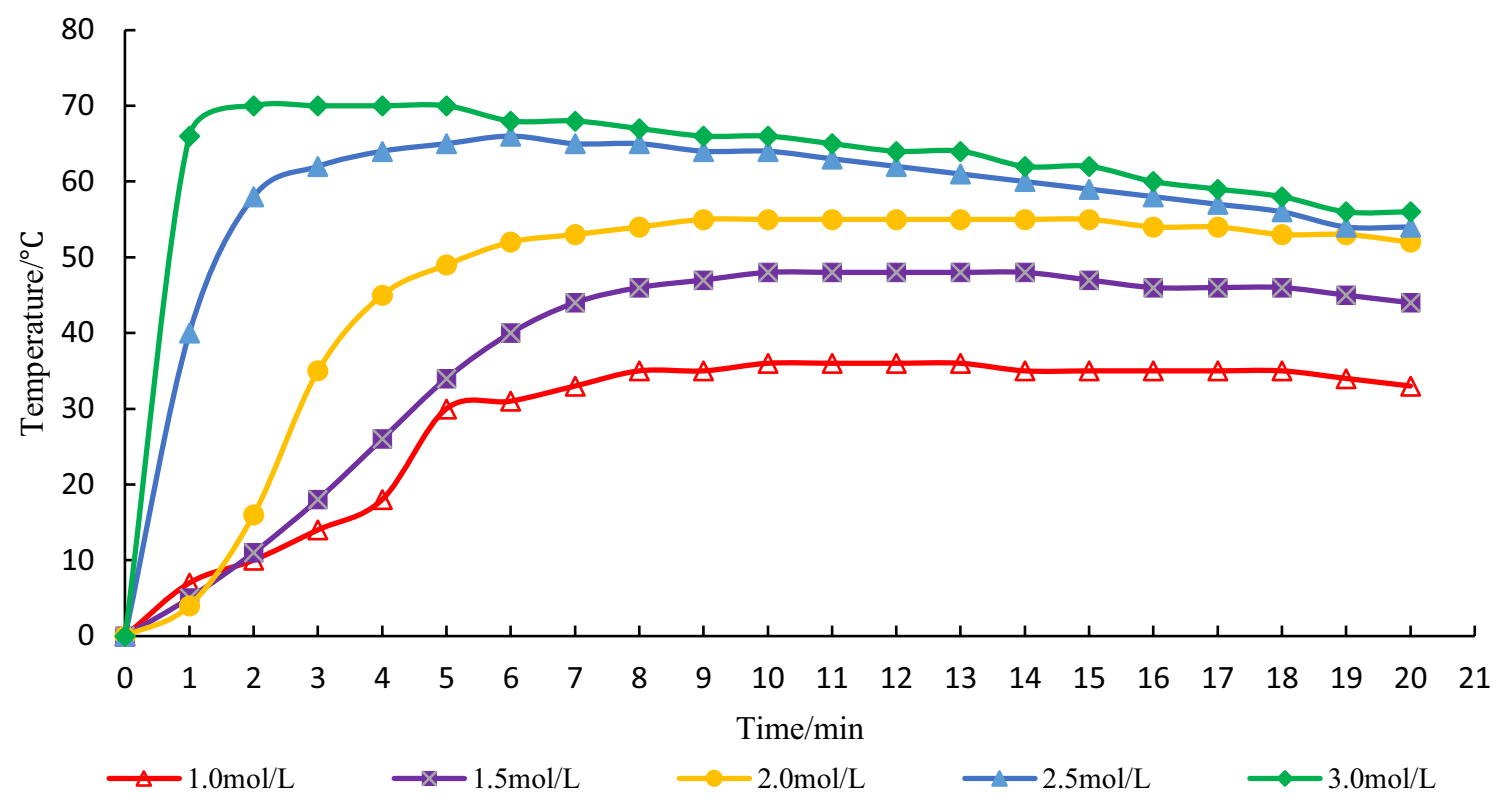

Fig. 2 Heating performance of different concentrations of heat-generating agents A and B

insulation instrument, temperature records were taken every minute, and the experiment records were stopped when the temperature began to decrease. The experimental results are shown in Fig. 2.

It can be seen from Fig. 2 and Table 3 that the higher the concentration of the heat-generating agent, the higher the peak temperature of the heat-generating reaction and the faster the heat-generating rate. The peak temperature of the heat-generation reaction with $3 \mathrm{~mol} / \mathrm{L}$ heat-generating agent was the largest, and the heat-generation rate was the fastest. According to the reservoir characteristics of XX oilfield, the temperature-increasing interval of the in situ heat system was $50-60^{\circ} \mathrm{C}$, so $1-2 \mathrm{~mol} / \mathrm{L}$ heat-generating agents $\mathrm{A}$ and $\mathrm{B}$ were the optimal range.

\section{Gas production}

The heat energy and gas production directly affect the performance of the entire workings of the in situ heat system and are thus the main indicators used to evaluate its performance. The type of heat-generating agent leads to different heat energy and gas production rates.

At room temperature, heat-generating agents $\mathrm{A}$ and $\mathrm{B}$ were used to test the system's pressure-boosting performance. The concentration gradient was set to $0.5 \mathrm{~mol} / \mathrm{L}$, and the concentration range was set to $1-2.5 \mathrm{~mol} / \mathrm{L}$. To test the in situ heat system with heat-generating agents $\mathrm{A}$ and $\mathrm{B}, 2 \%$ 1 \# catalyst was selected. For each group, the total volume of the solution was $500 \mathrm{~mL}$. The pressure measurement experiment was performed in a high-temperature, high-pressure corrosion instrument, and the pressure was recorded once every minute. When the pressure remained constant, the recording was stopped.

It can be seen in Fig. 3 that the greater the concentration of the heat-generating agent, the greater the heat-generating reaction rate. The $2.5 \mathrm{~mol} / \mathrm{L}$ heat-generating agent concentration had the highest reaction peak pressure and the fastest heat-generation rate. The higher the concentration of the heat-generating agent, the faster the peak pressure of the heat-generating reaction was reached. The gas generated by the in situ heat system can improve the fluid flow capacity during fracturing construction and boost pressure to help discharge. However, the larger pressure value has potential safety hazards, so a moderate pressure boost value of the heat-generating agent concentration range can be selected. According to the temperature increase interval, the gas production of the heat-generating system with 1-2 mol/L heat-generating agents $\mathrm{A}$ and $\mathrm{B}$ can achieve better pressureboosting and fracturing fluid drainage. As such, the optimal concentration of the heat-generating agent is $1-2 \mathrm{~mol} / \mathrm{L}$.

Table 3 Relationship between different reactant concentrations and peak temperature in the heat-generating agents $\mathrm{A}$ and $\mathrm{B}$ system

\begin{tabular}{lll}
\hline $\begin{array}{l}\text { Reactant concentration } \\
(\mathrm{mol} / \mathrm{L})\end{array}$ & Peak temperature $\left({ }^{\circ} \mathrm{C}\right)$ & $\begin{array}{l}\text { Arrival } \\
\text { time } \\
(\mathrm{min})\end{array}$ \\
\hline 1.0 & 55 & 10 \\
1.5 & 68 & 10 \\
2.0 & 75 & 9 \\
2.5 & 86 & 6 \\
3.0 & 90 & 2 \\
\hline
\end{tabular}




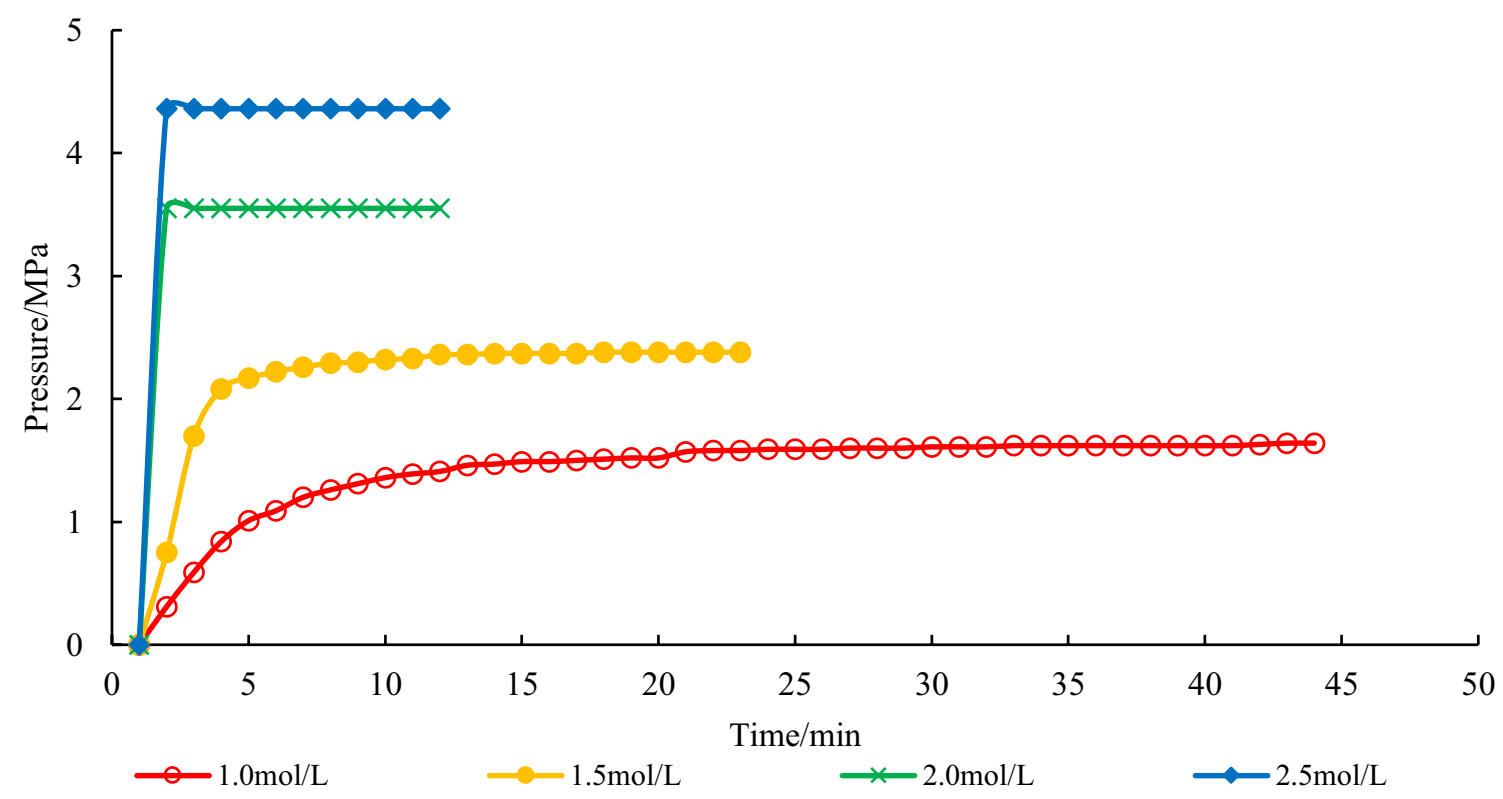

Fig. 3 Pressure-boosting performance of different concentrations of heat-generating agents

\section{Performance evaluation and optimization of in situ heat fracturing fluid system}

The in situ heat/gas clean foam fracturing fluid system generates heat and gas in situ. As the reservoir temperature increases, the system pressurizes and expands, foaming in situ and forming foam-like fracturing fluid. The system can reduce fluid loss, effectively crosslink and carry sand, and has good gel-breaking and reflow performance. The fracturing fluid system consists of heat-generating agent $\mathrm{A}+$ heat-generating agent $\mathrm{B}+1$ \# catalyst +506 thickener +506 crosslinking agent ${ }^{3}+$ gel breaker + low-temperature breaker + clay stabilizer + fracturing assistant $+\mathrm{pH}$ regulator; thus, the system is suitable for low-temperature, low-pressure, low-permeability reservoirs containing waxbearing heavy oil. The in situ heat/gas clean foam fracturing fluid is a low-damage fracturing fluid with low residue, low fluid loss, low corrosivity, good foam stabilization performance, and strong self-pressurization ability. The backflow liquid is nontoxic and has low corrosion. This is a fracturing fluid system with better economic benefits than other in situ heat fracturing fluid systems. Due to the mixing reaction between the heat-generating agents in the in situ heat system, this article divides the preparation of the fracturing fluid system into two parts. The base fluid consists of 506 thickener + heat-generating agent $\mathrm{A}+$ water, while the crosslinked

\footnotetext{
${ }^{3}$ The 506 thickener and 506 crosslinking agent are fracturing fluid additives that can effectively crosslink and carry sand in an acidic environment and have good gel breaking.
}

fluid comprises 506 crosslinking agent + gel breaker + heatgenerating agent $\mathrm{B}+$ low-temperature breaker + water. The performance evaluation and system optimization of the in situ heat clean fracturing fluid system were carried out.

\section{Experiment}

\section{Sand-carrying performance evaluation and optimization}

According to the performance evaluation and optimization results of the in situ heat-generation system, the optimal concentration of heat-generating agents $A$ and $B$ ranges between 1 and $2 \mathrm{~mol} / \mathrm{L}$. The heat-generation system ideal for the reservoir was finally determined to be $6.8 \%$ heat-generating agent $\mathrm{A}, 7 \%$ heat-generating agent $\mathrm{B}$, and $0.9 \% 1$ \# catalyst. While generating heat, the in situ heat fracturing fluid also generates a large amount of inert gas, and the system forms a foam-like fracturing fluid with a certain viscosity. The presence of foam increases the structural viscosity of the system, further enhances the sand-carrying capacity of the fracturing fluid, reduces the loss of the fracturing fluid, does not cause fracture wall damage, and can effectively reduce invasion damage to the reservoir. Using the determined optimal concentration of the heat-generating agent and catalyst, the sand-carrying performance evaluation of the fracturing fluid system and the system concentration were optimized.

1. Four groups of experiments were conducted to test the effect of thickener concentration. The fracture fluid sand-carrying experiment was carried out in $65^{\circ} \mathrm{C}$ water. The fracturing fluid thickener concentrations were

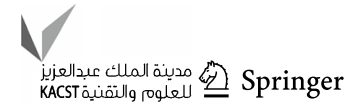


$0.2 \%, 0.3 \%, 0.4 \%$, and $0.5 \%$; the crosslinking agent concentration was $0.3 \%$; the gel-breaker concentration was $0.2 \%$; the proppant was $20 / 40$ mesh ceramsite; and the sand-liquid ratio was $25 \%$. Photographic observations were obtained at 30-min intervals, and the measurement duration was $2 \mathrm{~h}$.

2. Three groups of experiments were conducted to test the effect of crosslinking agent concentration. The fracture fluid sand-carrying experiment was conducted in $65^{\circ} \mathrm{C}$ water. The fracturing fluid thickener concentration was $0.3 \%$; the crosslinking agent concentrations were $0.2 \%$, $0.3 \%$, and $0.4 \%$; the gel-breaker concentration was $0.2 \%$; the proppant was 20/40 mesh ceramsite; and the sandliquid ratio was $25 \%$. Photographic observations were obtained at 30-min intervals, and the measurement duration was $2 \mathrm{~h}$.

3. Four groups of experiments were conducted to test the effect of gel-breaker concentrations. The fracture fluid sand-carrying experiment was conducted in $65^{\circ} \mathrm{C}$ water. The fracturing fluid thickener concentration was $0.3 \%$; the crosslinking agent concentration was $0.3 \%$; the gelbreaker concentrations were $0.2 \%, 0.3 \%$, and $0.4 \%$; the proppant was 20/40 mesh ceramsite; and the sand-liquid ratio was $25 \%$. Photographic observations were obtained at 30-min intervals, and the measurement duration was $2 \mathrm{~h}$.

\section{Evaluation and optimization of heating performance}

Due to the influence of viscosity, foam, salt, and other acidic agents, the temperature rise performance of the in situ heat fracturing fluid system was affected. According to the evaluation and optimization results of the sand-carrying performance of the fracturing fluid system, the thickener concentration was selected to be $0.3 \%$, and the temperature rise performance of the system was evaluated and optimized by changing the concentration of other fracturing fluid additives.

1. At room temperature, three groups of experiments were conducted to test the effect of crosslinking agent concentration on the system's temperature rise performance. The concentration of the thickener was $0.3 \%$; the gel-breaker concentration was $0.2 \%(0.2 \%, 0.3 \%$, $0.4 \%, 0.5 \%$ gel-breaker concentration, take the minimum gel-breaker concentration); the low-temperature breaker concentration was $0.2 \%(0.1 \%, 0.2 \%, 0.3 \%$ lowtemperature breaker concentration, take the median lowtemperature breaker concentration); and the crosslinker concentrations were $0.2 \%, 0.3 \%$, and $0.4 \%$. The total volume of each group of solution was $500 \mathrm{~mL}$, and the temperature measurement experiment was carried out in a high-temperature, high-pressure corrosion instrument.
The temperature was recorded once every minute, and the experiment recording was stopped when the temperature began to decrease.

2. At room temperature, four groups of experiments were conducted to test the effect of gel-breaker concentration on the system's temperature rise performance. The concentration of the thickener was $0.3 \%$; the concentration of the crosslinking agent was $0.3 \%(0.2 \%, 0.3 \%$, $0.4 \%$ crosslinking agent concentration, take the median crosslinking agent concentration); the concentration of the low-temperature breaker was $0.2 \%(0.1 \%, 0.2 \%$, $0.3 \%$ low-temperature breaker concentration, take the median low-temperature breaker concentration); and the concentrations of the gel breaker were $0.2 \%, 0.3 \%$, $0.4 \%$, and $0.5 \%$. The total volume of each group of solution was $500 \mathrm{~mL}$, and the temperature measurement experiment was carried out in a high-temperature, high-pressure corrosion instrument. The temperature was recorded once every minute, and the experiment recording was stopped when the temperature began to decrease.

3. At room temperature, three groups of experiments were conducted to test the effect of the low-temperature breaker concentration on the system's temperature rise performance. The concentration of the thickener was $0.3 \%$; the concentration of the crosslinking agent was $0.3 \%(0.2 \%, 0.3 \%, 0.4 \%$ crosslinking agent concentration, take the median crosslinking agent concentration); the concentration of the gel breaker was $0.2 \%(0.2 \%$, $0.3 \%, 0.4 \%, 0.5 \%$ gel-breaker concentration, take the minimum gel-breaker concentration); and the concentrations of the low-temperature breaker were $0.1 \%$, $0.2 \%$, and $0.3 \%$. The total volume of each group of solution was $500 \mathrm{~mL}$, and the temperature measurement experiment was carried out in a high-temperature, high-pressure corrosion instrument. The temperature was recorded once every minute, and the experiment recording was stopped when the temperature began to decrease.

\section{Evaluation and optimization of gel-breaking performance}

The in situ heat fracturing fluid should be low residue and low-damage, and the gel-breaking liquid should be clean and environmentally friendly to ensure heating and sand carrying. Due to the heat-generating reaction of the system in an acidic environment, conventional organic boron and other alkaline-environment crosslinking agents cannot be used. If organic zirconium is used as a fracturing fluid crosslinking agent, it would further increase the structural viscosity of the system and make system breaking more difficult. Therefore, a 506 crosslinking agent was selected as the crosslinking agent of the in situ heat fracturing fluid system. According to 
Table 4 Gel-breaking performance test of fracturing fluid system with different crosslinking agent concentrations $\left(65^{\circ} \mathrm{C}, 4 \mathrm{MPa}\right)$

\begin{tabular}{llll}
\hline $\begin{array}{l}\text { Crosslinker concen- } \\
\text { tration }(\%)\end{array}$ & Gel-breaking status & $\begin{array}{l}\text { Gel-breaking time } \\
\text { (h) }\end{array}$ & $\begin{array}{l}\text { Viscosity of the } \\
\text { gel-breaking liquid } \\
\text { (mPa s) }\end{array}$ \\
\hline 0.2 & Good gel-breaking performance & 2 & 2.2970 \\
0.3 & Good gel-breaking performance & 2 & 3.8014 \\
0.4 & Poor gel-breaking performance & 2 & 1.1816 \\
\hline
\end{tabular}

the evaluation and optimization results of the sand-carrying performance of the fracturing fluid system, the thickener concentration was selected to be $0.3 \%$, and the fracturing fluid system's gel-breaking performance was evaluated and optimized by changing the concentration of the fracturing fluid additive.

1. Three groups of experiments were conducted to test the effect of crosslinking agent concentration on breaker performance. The concentration of the thickener was $0.3 \%$; the concentration of the gel breaker was $0.2 \%$ $(0.2 \%, 0.3 \%, 0.4 \%, 0.5 \%$ gel-breaker concentration, take the minimum gel-breaker concentration); and the concentrations of the crosslinking agent were $0.2 \%, 0.3 \%$, and $0.4 \%$. A high-temperature, high-pressure corrosion instrument was set to heat to $65^{\circ} \mathrm{C}$ and pressurize at $4 \mathrm{MPa}$. After $2 \mathrm{~h}$ of gel breaking, the viscosity and surface tension of the gel-breaking liquid were measured, and the content of the gel-breaking residue was observed. The experimental results are shown in Table 4 and Fig. 16.

2. Four groups of experiments were conducted to test the effect of breaker concentration on breaker performance. The concentration of the thickener was $0.3 \%$; the concentration of the crosslinking agent was $0.3 \%(0.2 \%$, $0.3 \%, 0.4 \%$ crosslinking agent concentration, take the median crosslinking agent concentration); and the concentrations of the gel breaker were $0.2 \%, 0.3 \%, 0.4 \%$, and $0.5 \%$. The system was heated in $65{ }^{\circ} \mathrm{C}$ water, and the maximum breaking time of the system was estimated at the pressure of $0.1 \mathrm{MPa}$. The experimental results are shown in Table 5.

\section{Expansion and pressure-boosting performance evaluation and optimization}

The in situ heat fracturing fluid system automatically heats up, produces gas, and pressurizes, thus increasing the rate of fracturing fluid return. The resulting foam mixture significantly reduces the density of the fracturing fluid, lowers the wellbore pressure, and increases the pressure difference of the backflow. When the flowback occurs after the fracturing, the foam mixture is automatically gas-lifted in the wellbore and has a strong self-spraying ability. According to the experimentally determined dosage of the heat-generating agent, the concentration of the fracturing fluid additive was changed, and the expansion and pressurization performance test was carried out in a high-temperature, high-pressure corrosion instrument

1. At room temperature, three groups of experiments were conducted to test the effect of crosslinking agent concentration on the system's expansion and pressure-boosting performance. The concentration of the thickener was $0.3 \%$; the concentration of the gel breaker was $0.2 \%$; the concentration of the low-temperature breaker was $0.2 \%$; and the concentrations of the crosslinker were $0.2 \%, 0.3 \%$, and $0.4 \%$. The total volume of each solution was $500 \mathrm{~mL}$. The pressure measurement experiment was carried out in a high-temperature, high-pressure corrosion instrument. The pressure was recorded once every minute, and the experiment recording was stopped when the pressure remained constant.

2. At room temperature, four groups of experiments were conducted to test the effect of gel-breaker concentration on the system's expansion and pressure-boosting performance. The concentration of the thickener was $0.3 \%$; the concentration of the crosslinking agent was $0.3 \%$; the concentration of the low-temperature breaker was $0.2 \%$; and the concentrations of the crosslinkers were $0.2 \%$, $0.3 \%, 0.4 \%$, and $0.5 \%$. The total volume of each solution was $500 \mathrm{~mL}$. The pressure measurement experiment was carried out in a high-temperature, high-pressure corrosion instrument. The pressure was recorded once every minute, and the experiment recording was stopped when the pressure remained constant.

Table 5 Gel-breaking performance test of fracturing fluid system with different gel-breaker concentrations $\left(65^{\circ} \mathrm{C}, 0.1 \mathrm{MPa}\right)$

\begin{tabular}{lll}
\hline $\begin{array}{l}\text { Gel-breaker } \\
\text { concentration } \\
(\%)\end{array}$ & Gel-breaking status & Gel-breaking time \\
\hline 0.2 & Good gel-breaking performance & $13 \mathrm{~h} 30 \mathrm{~min}$ \\
0.3 & Good gel-breaking performance & $9 \mathrm{~h}$ \\
0.4 & Good gel-breaking performance & $6 \mathrm{~h} 30 \mathrm{~min}$ \\
0.5 & Good gel-breaking performance & $5 \mathrm{~h} 30 \mathrm{~min}$ \\
\hline
\end{tabular}


Table 6 Corrosion test of crosslinking fluid without the corrosion inhibitor

\begin{tabular}{lll}
\hline N80 steel sheet number & 590 & 591 \\
Size $(\mathrm{mm})$ & $10.07 \times 3.01 \times 50.05$ & $9.96 \times 2.88 \times 50.03$ \\
Weight $(\mathrm{g})$ & 11.2895 & 10.9348 \\
Weight after $2 \mathrm{~h}(\mathrm{~g})$ & 11.2589 & 10.904 \\
Corrosion rate $\left(\mathrm{g} /\left(\mathrm{m}^{2} \mathrm{~h}\right)\right)$ & 11.1685 & 11.4742 \\
Average corrosion rate $\left(\mathrm{g} /\left(\mathrm{m}^{2} \mathrm{~h}\right)\right)$ & 11.3214 & \\
\hline
\end{tabular}

Table 7 Corrosion test of crosslinking fluid with the corrosion inhibitor

\begin{tabular}{lll}
\hline N80 steel sheet number & 563 & 568 \\
Size $(\mathrm{mm})$ & $10.1 \times 2.96 \times 50.03$ & $10.02 \times 3.05 \times 50.04$ \\
Weight $(\mathrm{g})$ & 11.177 & 11.3404 \\
Weight after $2 \mathrm{~h}(\mathrm{~g})$ & 11.1646 & 11.3274 \\
Corrosion rate $\left(\mathrm{g} /\left(\mathrm{m}^{2} \mathrm{~h}\right)\right)$ & 4.5369 & 4.7474 \\
Average corrosion rate $\left(\mathrm{g} /\left(\mathrm{m}^{2} \mathrm{~h}\right)\right)$ & 4.6422 & \\
\hline
\end{tabular}

3. At room temperature, three groups of experiments were conducted to test the effect of low-temperature breaker concentration on the system's expansion and pressureboosting performance. The concentration of the thickener was $0.3 \%$; the concentration of the crosslinking agent was $0.3 \%$; the concentration of the gel breaker was $0.2 \%$; and the concentrations of the crosslinker were $0.1 \%, 0.2 \%$, and $0.3 \%$. The total volume of each solution was $500 \mathrm{~mL}$. The pressure measurement experiment was carried out in a high-temperature, high-pressure corrosion instrument. The pressure was recorded once every minute, and the experiment recording was stopped when the pressure remained constant.

\section{Rheological property evaluation}

Through the performance evaluation and optimization experiments of the fracturing fluid system, the formula of the in situ heat fracturing fluid that meets the performance evaluation criteria of the water-based fracturing fluid was selected, and the fracturing fluid rheology test was conducted.

The concentration of the thickener was $0.3 \%$, the concentration of the crosslinking agent was $0.3 \%$, and the concentration of the breaker was $0.2 \%$. A solution consisting of thickener + heat-generating agent $\mathrm{A}+$ water was used to prepare the base liquid, and a solution consisting of a crosslinking agent + gel breaker + heat-generating agent $\mathrm{B}+$ low-temperature breaker was used to prepare the crosslinking liquid. The ratio of base liquid to crosslinking liquid was 12:8. For the rheological performance test, the rheometer was set at $170 \mathrm{~s}^{-1}$, and the temperature range was $20-70{ }^{\circ} \mathrm{C}$.

\section{Evaluation of corrosion performance}

The in situ heat fracturing fluid system is pumped into the formation for fracturing construction, and the corrosion performance of the system must be evaluated. Due to the heat generation, gas production, and acid characteristics of the system itself, a corrosion performance test can effectively evaluate the corrosion of the oil casing.

1. Since the $\mathrm{pH}$ value of the base fluid in the fracturing fluid system is neutral, and the $\mathrm{pH}$ value of the crosslinking fluid is acidic, a corrosion test was conducted on the crosslinking fluid. The formula of the experimental crosslinking liquid was $0.3 \%$ crosslinking agent $+0.2 \%$ gel breaker $+0.2 \%$ low-temperature breaker $+7 \%$ heatgenerating agent $\mathrm{B}+0.9 \%$ catalyst + water. The total volume of the solution was $250 \mathrm{~mL}$. The N80 steel sheets were used for a 2 -h static corrosion test in a $65{ }^{\circ} \mathrm{C}$ water bath. The results are shown in Table 6 and Fig. 19 .

2 . To again conduct the crosslinking solution corrosion test, a $0.1 \%$ corrosion inhibitor was added to the crosslinking solution. The formula of the experimental crosslinking liquid was $0.3 \%$ crosslinking agent $+0.2 \%$ gel breaker $+0.2 \%$ low-temperature breaker $+0.1 \%$ corrosion inhibitor $+7 \%$ heat-generating agent $\mathrm{B}+0.9 \%$ catalyst + water. The total volume of the solution was $250 \mathrm{~mL}$. The N80 steel sheets were used for a 2-h static corrosion test in a $65{ }^{\circ} \mathrm{C}$ water bath. The results are shown in Table 7 and Fig. 20.

3. The corrosion test of the in situ heat fracturing fluid was performed in a high-temperature, high-pressure corrosion instrument. The formula of the experimental base fluid was $0.3 \%$ thickener $+6.8 \%$ heat-generating agent $\mathrm{A}+$ water, and the formula of the crosslinking fluid 
Table 8 Corrosion test of fracturing fluid without the corrosion inhibitor

\begin{tabular}{lll}
\hline N80 steel sheet number & 503 & 589 \\
Size $(\mathrm{mm})$ & $10.05 \times 2.85 \times 50.05$ & $9.89 \times 2.9 \times 50.07$ \\
Weight $(\mathrm{g})$ & 10.774 & 10.781 \\
Weight after $2 \mathrm{~h}(\mathrm{~g})$ & 10.7633 & 10.7707 \\
Corrosion rate $\left(\mathrm{g} /\left(\mathrm{m}^{2} \mathrm{~h}\right)\right)$ & 3.9672 & 3.8486 \\
Average corrosion rate $\left(\mathrm{g} /\left(\mathrm{m}^{2} \mathrm{~h}\right)\right)$ & 3.9079 & \\
\hline
\end{tabular}

Fig. 4 The sand-carrying condition of an in situ heat fracturing fluid system containing $0.2 \%$ thickener heated in a $65^{\circ} \mathrm{C}$ water bath for $30,60,90$, and $120 \mathrm{~min}$

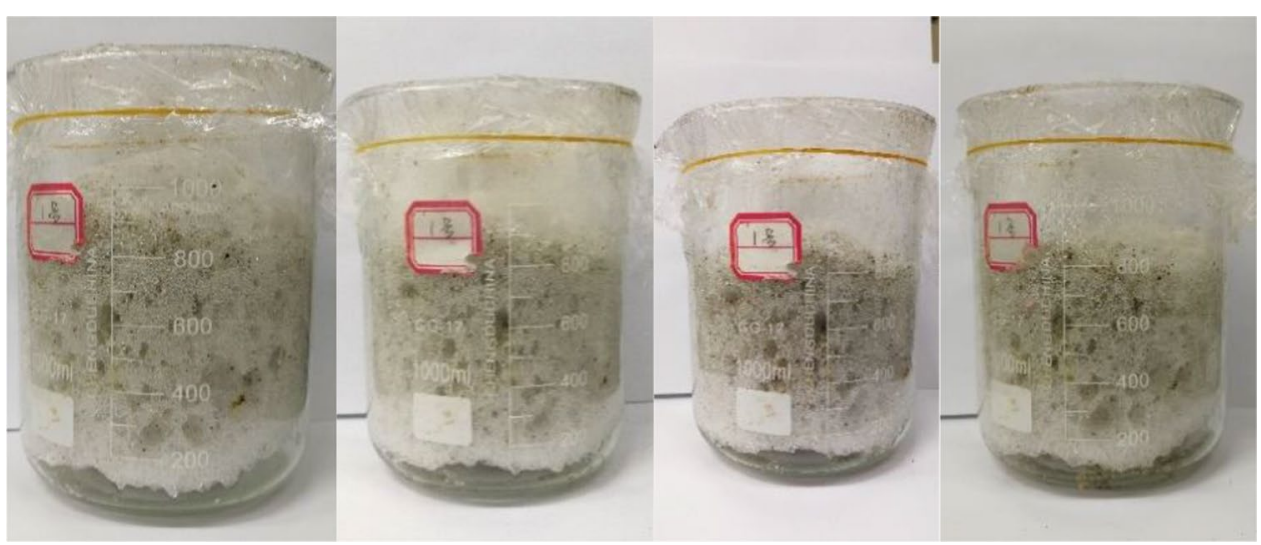

Fig. 5 The sand-carrying condition of an in situ heat fracturing fluid system containing $0.3 \%$ thickener heated in a $65^{\circ} \mathrm{C}$ water bath for $30,60,90$, and $120 \mathrm{~min}$

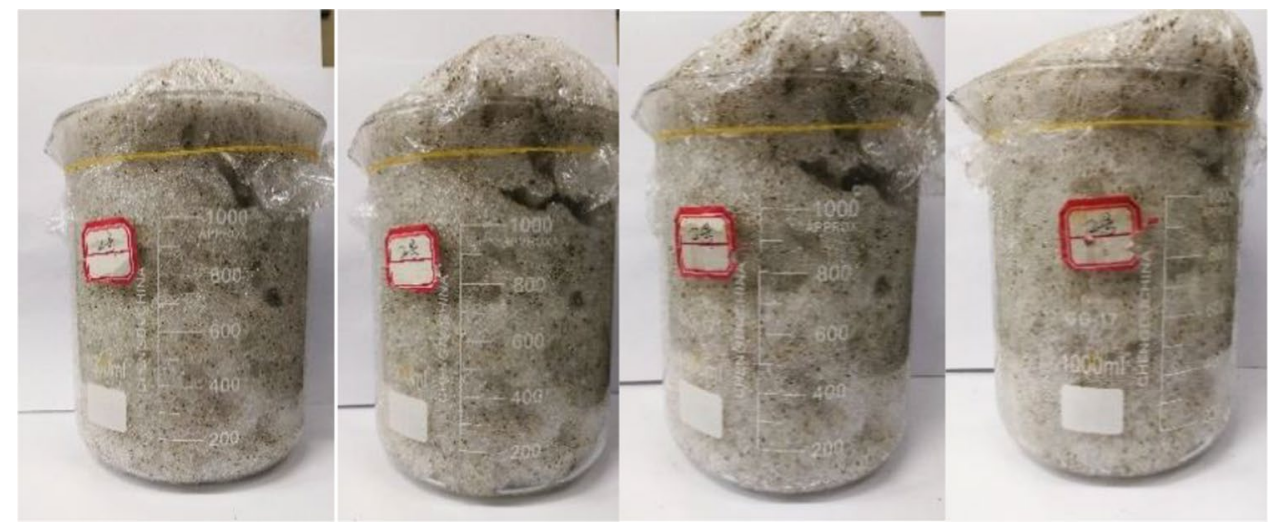

was $0.3 \%$ crosslinking agent $+0.2 \%$ gel breaker $+0.2 \%$ low-temperature breaker $+7 \%$ heat-generating agent $\mathrm{B}+0.9 \%$ catalyst + water. The total volume of the solution was $250 \mathrm{~mL}$. The N80 steel sheets were used for a 2-h static corrosion test in a $65^{\circ} \mathrm{C}$ water bath. The results are shown in Table 8 and Fig. 21.

\section{Results and discussion}

\section{Sand-carrying performance evaluation and optimization}

After the crosslinking liquid and proppant were added to the base fluid and stirred to form a jelly, the system automatically generates heat/gas to form a foam-like fracturing fluid, the volume continues to expand, and the proppant continues to rise as the system expands. The sand-carrying performance of the system was evaluated using a sand-carrying performance of the experiment and was found to be good: The proppant was evenly distributed overall, and the sedimentation rate approached zero.

Experiment 1 See Figs. 4, 5, 6, and 7.

Experiment 2 See Figs. 8, 9, and 10.

Experiment 3 See Figs. 11, 12, 13, and 14.

In Experiment 1, as shown in Figs. 4, 5, 6, and 7, as the concentration of thickener increased, the system's expansion and pressure-boosting performance, the structural viscosity of the foam-like fracturing fluid, and the sandcarrying performance of the system all improved. In the experimental group with $0.2 \%$ thickener, the structural 


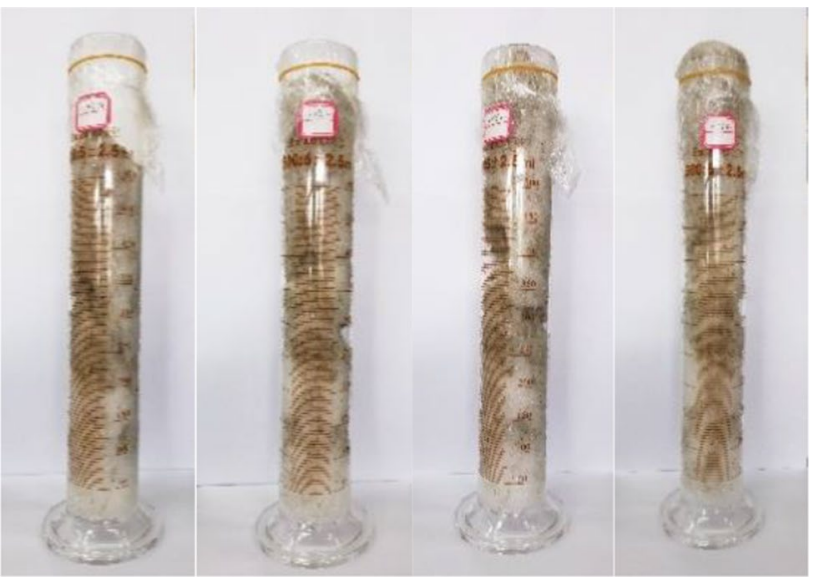

Fig. 6 The sand-carrying condition of an in situ heat fracturing fluid system containing $0.4 \%$ thickener heated in a $65^{\circ} \mathrm{C}$ water bath for 30 , 60,90 , and $120 \mathrm{~min}$

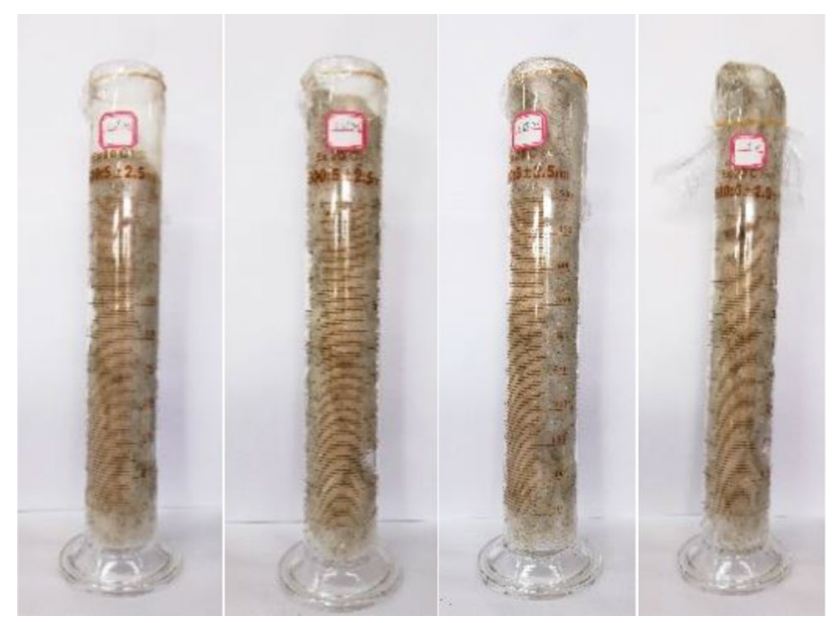

Fig. 7 The sand-carrying condition of an in situ heat fracturing fluid system containing $0.5 \%$ thickener heated in a $65^{\circ} \mathrm{C}$ water bath for 30 , 60,90 , and $120 \mathrm{~min}$

viscosity of the foam-like fracturing fluid decreased due to the pre-breaking of the gel, the sand-carrying capacity of the system decreased, and the proppant appeared to settle. Therefore, the concentration of thickener should not be less than $0.3 \%$ in the sand-carrying experiment. In Experiment 2, as shown in Figs. 8, 9, and 10, the concentration of the thickening agent was $0.3 \%$. By changing the concentration of the crosslinking agent, the optimal amount of the crosslinking agent at the concentration of the thickening agent was preferable. As the concentration of the crosslinking agent increased, the system's expansion, pressure-boosting performance, and sand-carrying performance improved. However, when the crosslinking agent concentration exceeds $0.3 \%$, there is no obvious change in the system's expansion, pressure-boosting, or

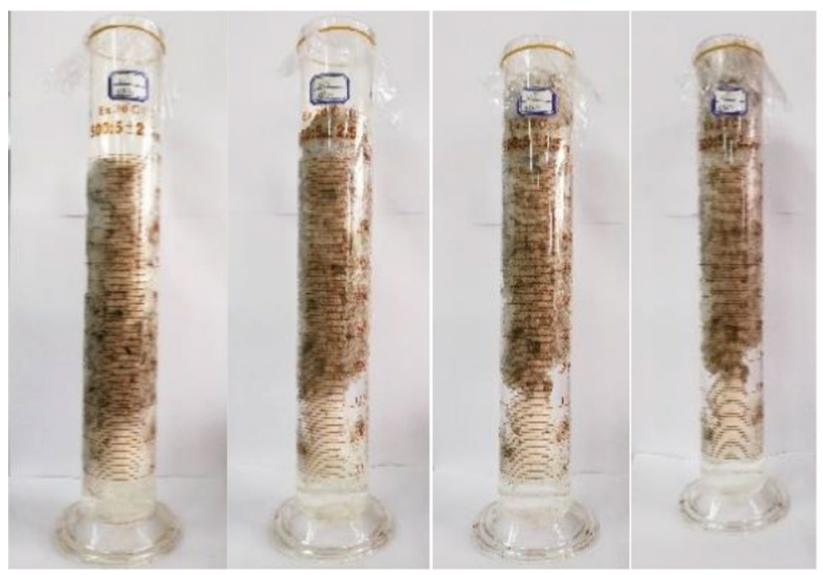

Fig. 8 The sand-carrying condition of an in situ heat fracturing fluid system containing $0.2 \%$ crosslinking agent heated in a $65{ }^{\circ} \mathrm{C}$ water bath for $30,60,90$, and $120 \mathrm{~min}$

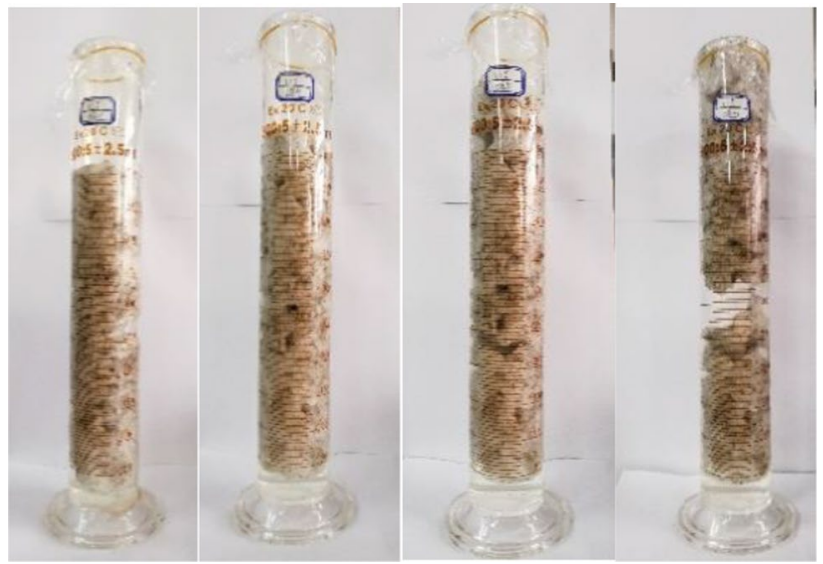

Fig. 9 The sand-carrying condition of an in situ heat fracturing fluid system containing $0.3 \%$ crosslinking agent heated in a $65{ }^{\circ} \mathrm{C}$ water bath for $30,60,90$, and $120 \mathrm{~min}$

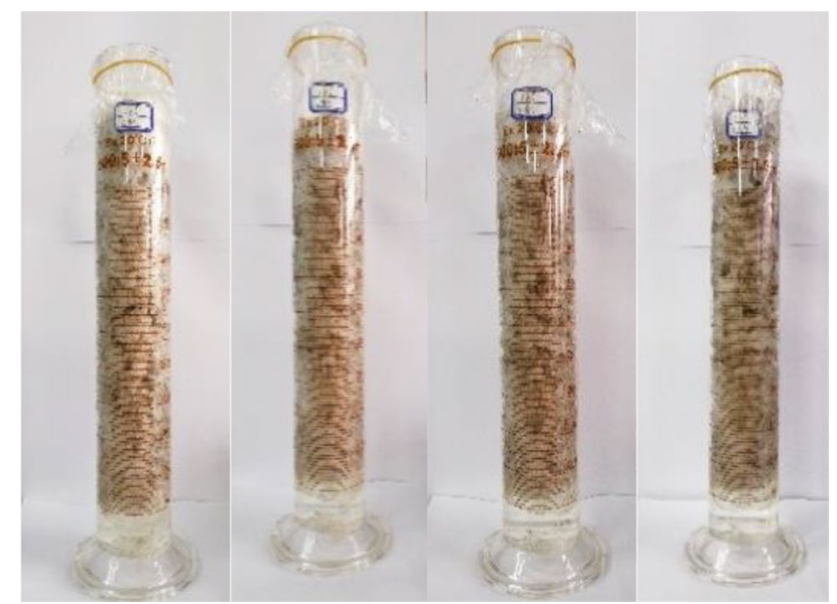

Fig. 10 The sand-carrying condition of an in situ heat fracturing fluid system containing $0.4 \%$ crosslinking agent heated in a $65{ }^{\circ} \mathrm{C}$ water bath for $30,60,90$, and $120 \mathrm{~min}$ 


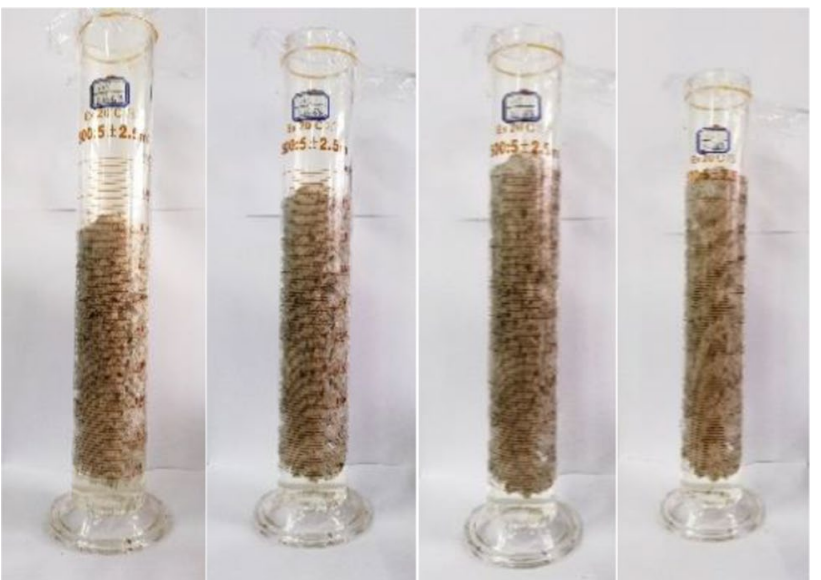

Fig. 11 The sand-carrying condition of an in situ heat fracturing fluid system containing $0.2 \%$ gel breaker heated in a $65{ }^{\circ} \mathrm{C}$ water bath for $30,60,90$, and $120 \mathrm{~min}$

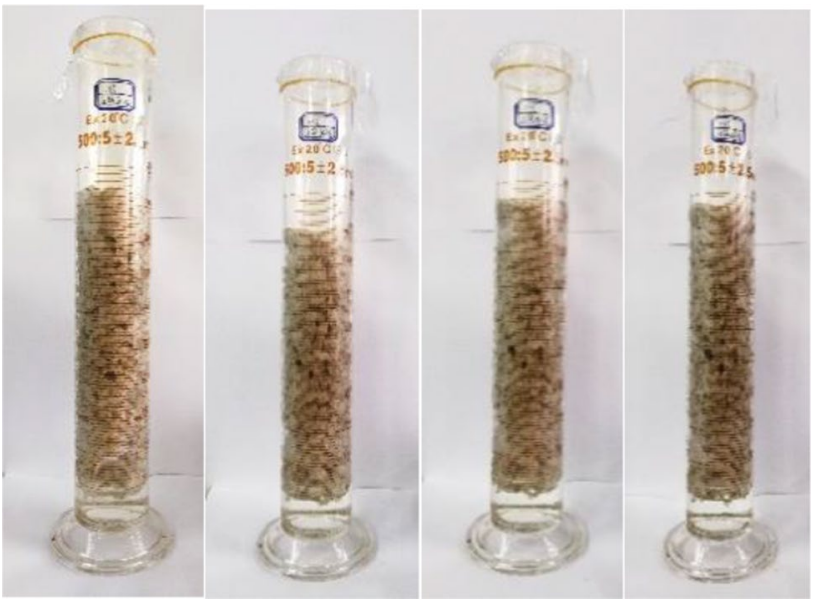

Fig. 12 The sand-carrying condition of an in situ heat fracturing fluid system containing $0.3 \%$ gel breaker heated in a $65{ }^{\circ} \mathrm{C}$ water bath for $30,60,90$, and $120 \mathrm{~min}$

sand-carrying performance. Thus, in the sand-carrying experiment with $0.3 \%$ thickener, ideally, the crosslinking agent concentration should not be less than $0.3 \%$. In Experiment 3, as shown in Figs. 11, 12, 13, and 14, the concentration of thickener and crosslinking agent were both $0.3 \%$, and the amount of gel breaker was changed to observe the fracturing fluid's sand-carrying performance. As the concentration of the gel breaker increased, after $2 \mathrm{~h}$ of heating in the water bath, the gel-breaking status of each group increased, and the sand-carrying capacity of the system decreased. Therefore, to ensure the best sandcarrying performance of the system with the $0.3 \%$ thickener and $0.3 \%$ crosslinking agent, a low concentration of gel breaker should be used.

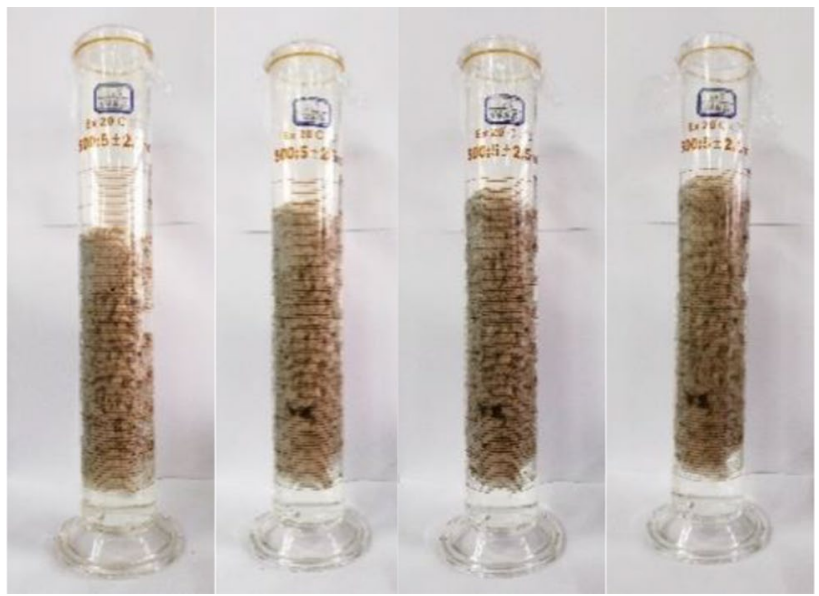

Fig. 13 The sand-carrying condition of an in situ heat fracturing fluid system containing $0.4 \%$ gel breaker heated in a $65{ }^{\circ} \mathrm{C}$ water bath for $30,60,90$, and $120 \mathrm{~min}$

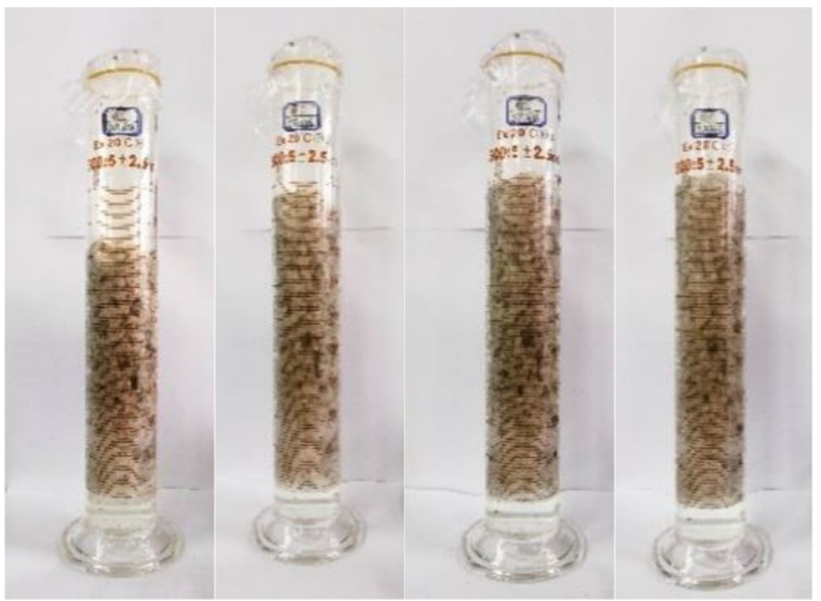

Fig. 14 The sand-carrying condition of an in situ heat fracturing fluid system containing $0.5 \%$ gel breaker heated in a $65{ }^{\circ} \mathrm{C}$ water bath for $30,60,90$, and $120 \mathrm{~min}$

\section{Evaluation and optimization of heating performance}

The temperature rise performance evaluation and optimization of the fracturing fluid additive were carried out under the determined concentrations of the heat-generating agent and thickening agent. The experimental results are shown in Fig. 15. It can be seen that different concentrations of fracturing fluid additives can have different effects on the temperature rise performance of the system. Of them, a group consisting of $0.3 \%$ thickener $+0.3 \%$ crosslinking agent $+0.2 \%$ gel breaker $+0.3 \%$ low-temperature breaker has the best heating performance (Fig. 16). 


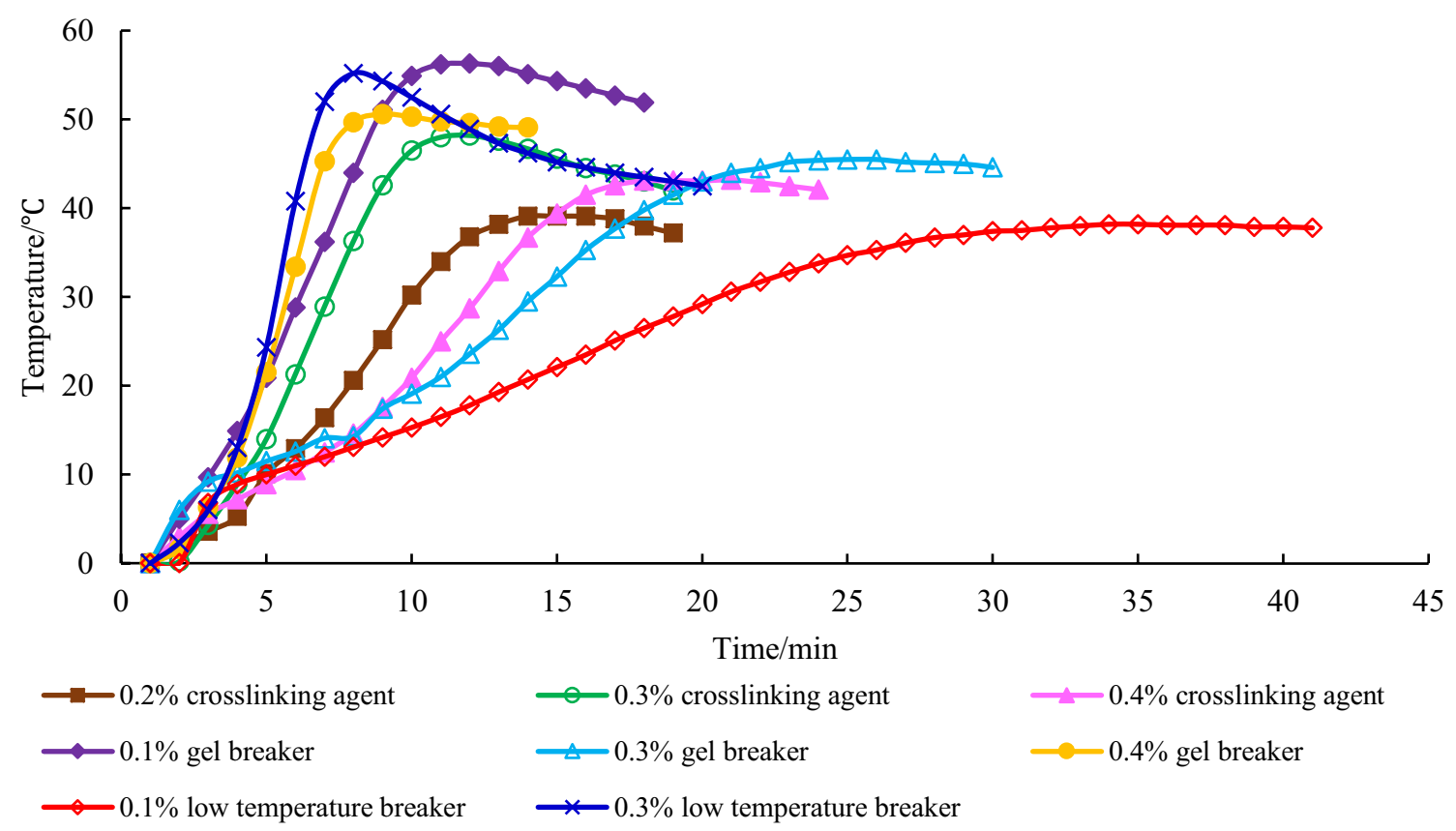

Fig. 15 Heating curves of different fracturing fluid additives

Fig. 16 Surface tension test of the gel-breaking fluid of the fracturing fluid system with $0.3 \%$ thickener, $0.3 \%$ crosslinker, and $0.2 \%$ gel breaker

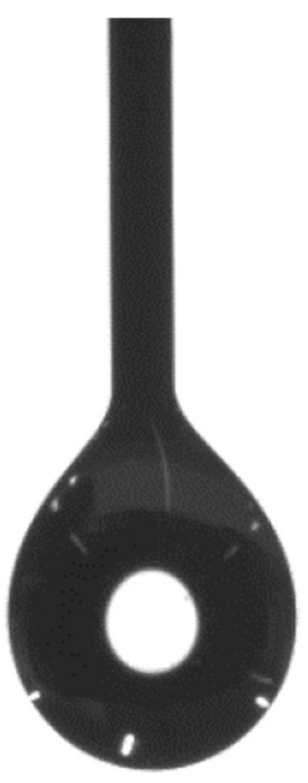

\section{Evaluation and optimization of gel-breaking performance}

The results of Experiment 1 show that system breaking can occur to varying degrees within $2 \mathrm{~h}$, and the crosslinking agent with a maximum concentration of $0.3 \%$ has good gel-breaking performance. The gel-breaking fluid viscosity of the $0.3 \%$ crosslinking agent is $3.8014 \mathrm{mPa}$, and the surface tension test result is $27.70 \mathrm{mN} / \mathrm{m}$, which is in line with the conventional water-based fracturing fluid breaking fluid standard. The results of Experiment 2 show that the time required for the system to completely break the gel is longer than that under $4 \mathrm{MPa}$. As the gel-breaker concentration increases, the time it takes for the system to completely break the gel decreases. By combining the sand-carrying experiment and the gel-breaking experiment, it can be preliminarily determined that the system's thickener concentration is $0.3 \%$, the crosslinking agent concentration is $0.3 \%$, and the gel-breaker concentration is $0.2 \%$.

\section{Expansion and pressure-boosting performance evaluation and optimization}

The expansion and pressure-boosting performance evaluation and optimization of the fracturing fluid additives were carried out under the determined concentrations of heatgenerating agent and thickening agent. The experimental results are shown in Fig. 17. It can be seen that different concentrations of fracturing fluid additives can have different effects on the expansion and pressure-boosting performance of the system. Of them, the group with $0.3 \%$ thickener $+0.3 \%$ crosslinking agent $+0.2 \%$ gel breaker $+0.2 \%$ low-temperature breaker has the highest pressure increase value, which is well suited to the evaluation and optimization experiment results of the sand-carrying and breaking performance of the system.

\section{Rheological property evaluation}

The rheological properties were evaluated with a fracturing fluid formula consisting of $0.3 \%$ thickener $+0.3 \%$ 


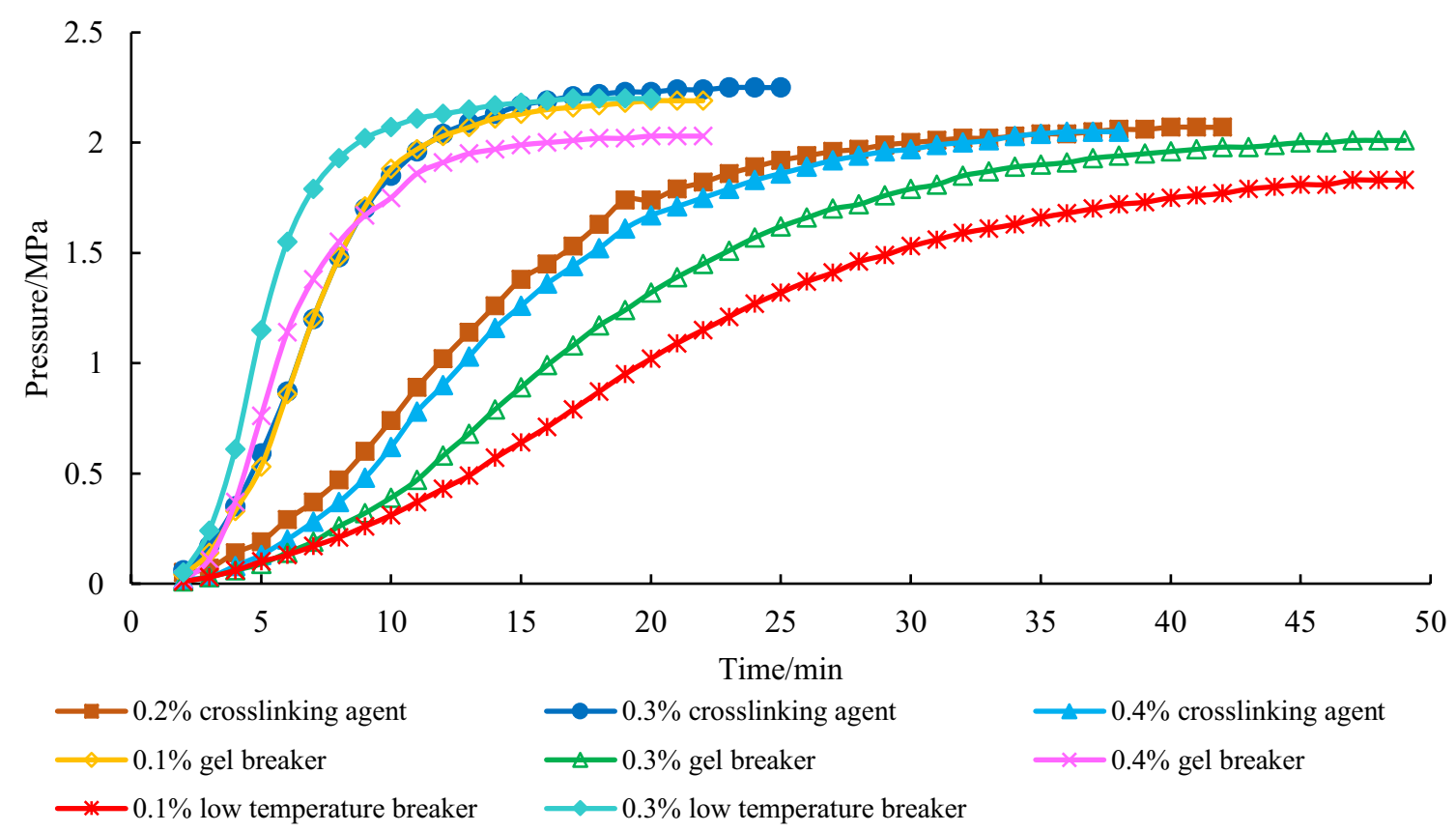

Fig. 17 Pressure-boosting performance of different fracturing fluid additive concentrations

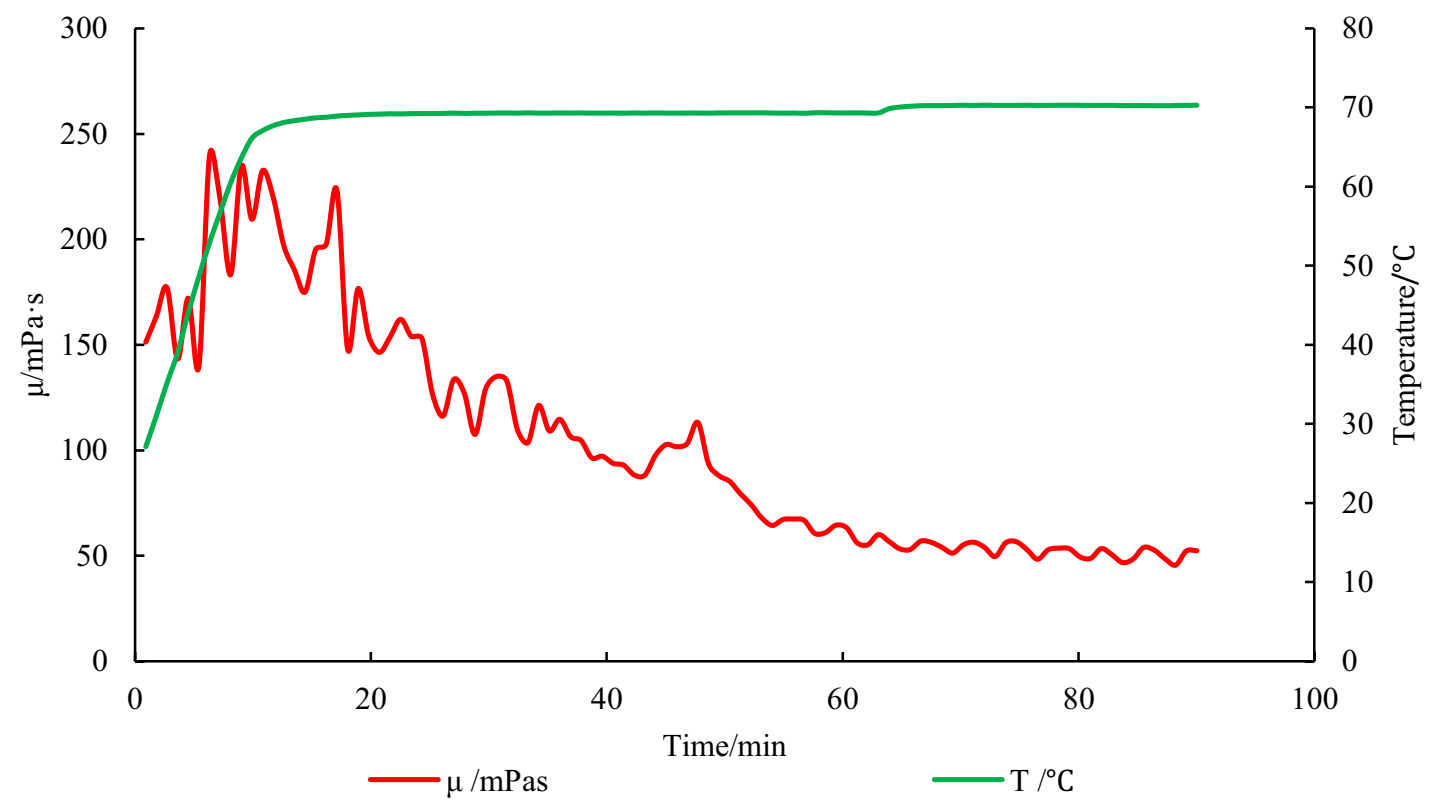

Fig. 18 Fracturing fluid rheological performance test with crosslinking ratio of 12:8

crosslinker $+0.2 \%$ gel breaker $+0.2 \%$ low-temperature breaker. The viscosity of the base liquid tested in the experiment was $36 \mathrm{mPa}$ s, and the crosslinking time was 40-50 s. The rheological performance evaluation results are shown in Fig. 18. It can be seen that within $20-70{ }^{\circ} \mathrm{C}$, the viscosity of the fracturing fluid is maintained above $50 \mathrm{mPa}$ for at least $1 \mathrm{~h}$, which meets the requirements of conventional water-based fracturing fluid systems. 
Fig. 19 Comparison photographs of N80 steel sheets before and after corrosion using a crosslinking fluid without the corrosion inhibitor

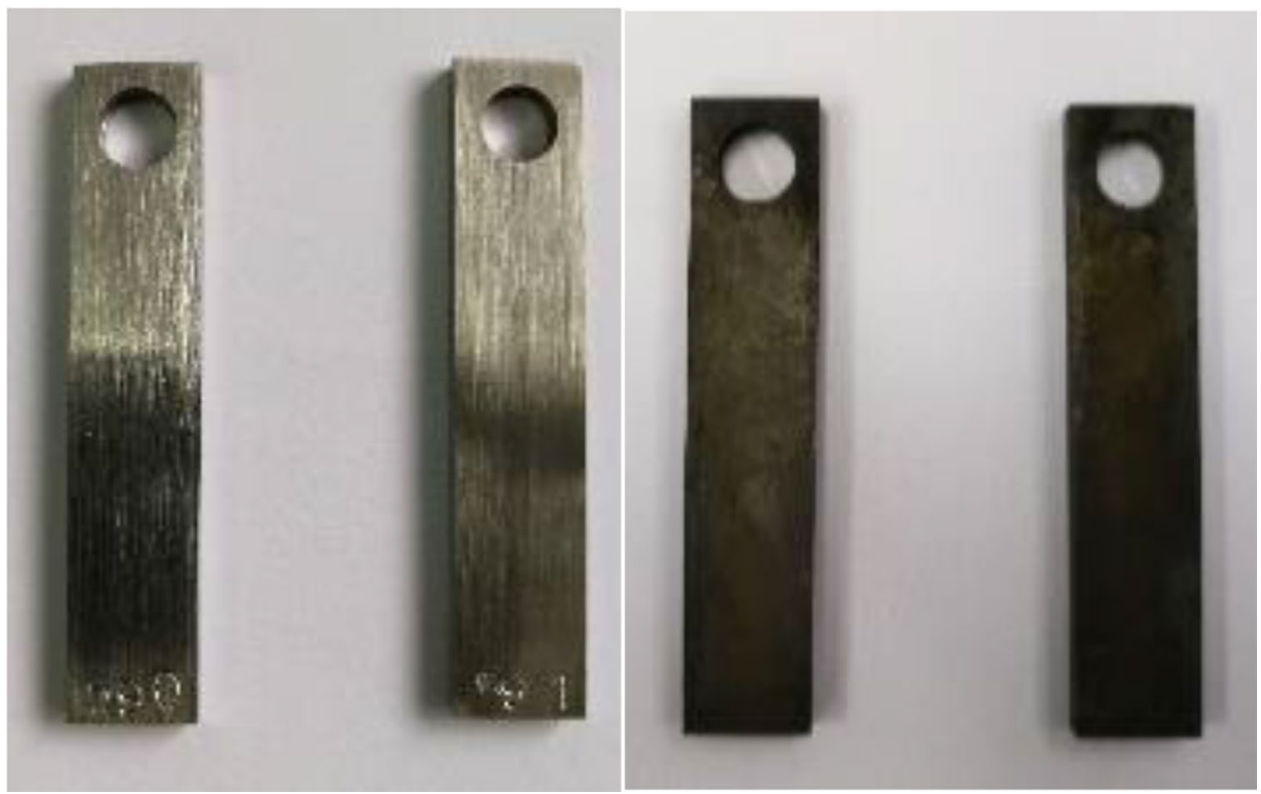

Fig. 20 Comparison photographs of N80 steel sheets before and after corrosion using a crosslinking fluid with the corrosion inhibitor

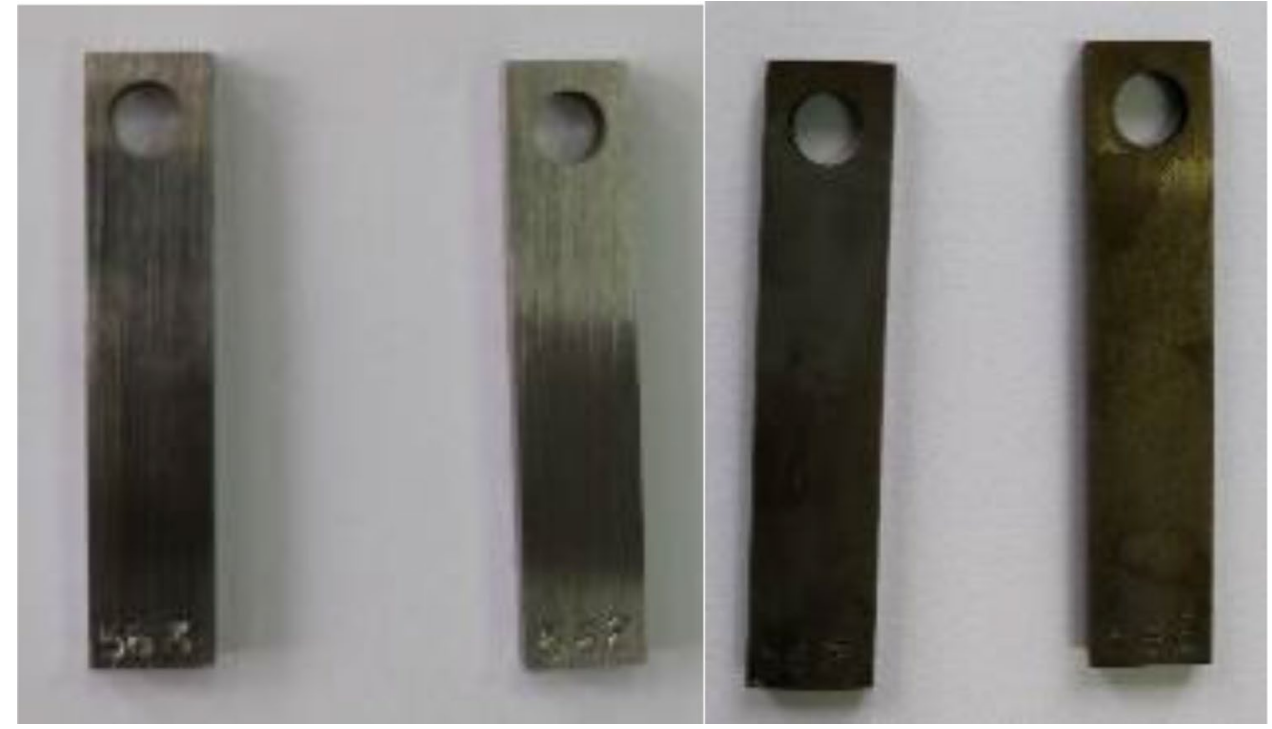

\section{Evaluation of corrosion performance}

In Experiment 1, as shown in Table 6, Fig. 19, the average corrosion rate of the crosslinking fluid without a corrosion inhibitor on the N80 steel sheet was $11.3214 \mathrm{~g} /\left(\mathrm{m}^{2} \mathrm{~h}\right)$, which is greater than the standard of the conventional water-based fracturing fluid, and the corrosion is serious. In Experiment 2, as shown in Table 7, Fig. 20, 1\% corrosion inhibitor was added to the crosslinking liquid of Experiment 1, and the experiment was performed again. The test resulted in a reduced corrosion rate of $4.6422 \mathrm{~g} /\left(\mathrm{m}^{2} \mathrm{~h}\right)$. In Experiment 3, as shown in Table 8, Fig. 21, the base fluid and the crosslinking fluid were mixed and crosslinked to produce a foam-like fracturing fluid system. The corrosion rate of the
$\mathrm{N} 80$ steel sheet was $3.9079 \mathrm{~g} /\left(\mathrm{m}^{2} \mathrm{~h}\right)$, which was lower than the standard of conventional water-based fracturing fluid. Therefore, the fracturing fluid system can effectively reduce the corrosion of the downhole string and meet the requirements of on-site construction.

\section{Experiment 1 See Fig. 19 and Table 6.}

\section{Experiment 2 See Fig. 20 and Table 7.}

\section{Experiment 3 See Fig. 21 and Table 8.}

According to the performance evaluation and optimization results of the in situ heat fracturing fluid system, it can be determined that the standard formula of the conventional 
Fig. 21 Comparison photographs of N80 steel sheets before and after corrosion using a fracturing fluid without the corrosion inhibitor

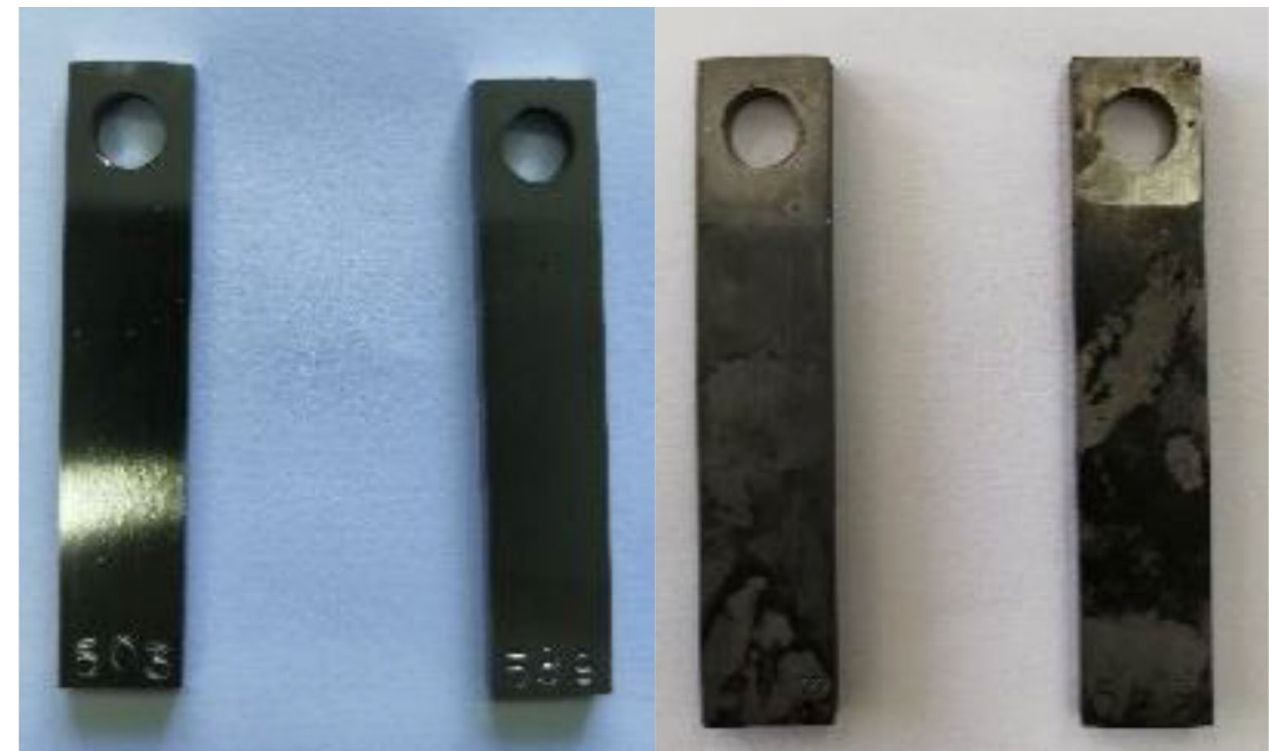

water-based fracturing fluid is $0.3 \%$ thickener $+0.3 \%$ crosslinking agent $+0.2 \%$ gel breaker $+0.2 \%$ low-temperature breaker $+6.8 \%$ heat-generating agent $\mathrm{A}+7 \%$ heatgenerating agent $\mathrm{B}+0.9 \% 1$ \# catalyst.

\section{Fracturing technology of in situ heat fracturing fluid system}

Due to the characteristics of in situ heat generation and gas production of the in situ heat fracturing fluid, during the preparation of in situ heat fracturing fluid system, the mixing of two heat-generating agents on the ground to generate heat must be avoided. Unlike the configuration of conventional water-based fracturing fluid, the on-site construction process of in situ heat fracturing fluid will also change accordingly. In this paper, the in situ heat fracturing fluid system is designed based on the stratum and well conditions of the construction well, and in situ heat fracturing technology is provided.

According to the reservoir characteristics of the XX oilfield, the final composition of the fracturing fluid system was determined to include $0.3 \%$ thickener, $0.2 \%$ crosslinking agent, $6.8 \%$ heat-generating agent $\mathrm{A}, 7 \%$ heat-generating agent B, $0.9 \% 1$ \# catalyst, $0.2 \%$ gel breaker, $0.2 \%$ lowtemperature breaker, $1.5 \%$ multifunctional additive, and the balance is water. The proppant uses 20/40 mesh ceramsite. Comprehensive consideration of reservoir thickness, porosity, permeability, saturation, fracture development status, sand body distribution range, wellbore conditions, surface equipment, optimization design and simulation through fracturing software, optimize based on the existing fracturing construction process, determine the construction scale.
Finally, $100 \mathrm{~m}^{3}$ fracturing fluid and $15 \mathrm{~m}^{3}$ for $20 / 40$ mesh ceramsite were determined to be optimal.

The base liquid and the crosslinking liquid were mixed at a crosslinking ratio of $9: 1$, that is, $90 \mathrm{~m}^{3}$ base liquid and $10 \mathrm{~m}^{3}$ crosslinking liquid. The base fluid was divided into two types, $\mathrm{A}$ and $\mathrm{B}$, which were mixed in a $1: 1$ ratio ( $45 \mathrm{~m}^{3}$ of each). The formula of base liquid A was $33.05 \mathrm{~m}^{3}$ water $+6.8 \mathrm{~m}^{3}$ heat-generating agent $\mathrm{A}+0.15 \mathrm{~m}^{3} 506$ thickener. After heat-generating agent $\mathrm{A}$ was dissolved in water, the 506 thickener was gradually added. After the liquid was dispensed, it was left for 2-5 h to allow for swelling. The formula of base liquid $B$ was $37.85 \mathrm{~m}^{3}$ water $+7 \mathrm{~m}^{3}$ heat-generating agent $\mathrm{B}+0.15 \mathrm{~m}^{3} 506$ thickener. After heat-generating agent $\mathrm{B}$ was dissolved in water, the 506 thickener was gradually added. After the liquid was dispensed, it was left for $2-5 \mathrm{~h}$ to allow for swelling. The formula of the crosslinking liquid was $7.2 \mathrm{~m}^{3}$ water $+0.9 \mathrm{~m}^{3} 1$ \# catalyst $+0.2 \mathrm{~m}^{3} 506$ crosslinking agent $+1.5 \mathrm{~m}^{3}$ multifunctional additive. Finally, $0.2 \mathrm{~m}^{3}$ gel breaker and $0.2 \mathrm{~m}^{3}$ low-temperature breaker were added prior to construction.

Base fluids A and B and crosslinking fluid were mixed in a sand-mixing truck through a three-way pipeline at a certain ratio. Simultaneously, proppant was added, and the mixture was evenly injected into the formation from the wellbore. When the construction sand proportion reached $25 \%$, $0.03 \mathrm{~m}^{3}$ gel breaker was added to the sand-mixing truck.

Fracturing was carried out in accordance with the following pumping procedures and construction parameters: construction displacement, construction pressure, sand ratio, sand volume, and liquid volume, all of which were recorded in a standardized manner. The liquid injection was required to be annulus. The maximum pump pressure could not exceed $25 \mathrm{MPa}$. The two gradient sand concentrations were slowly transitioned to avoid steep steps. 
1. High-pressure pumping pre-fluid: $15 \mathrm{~m}^{3}$ in situ heat fracturing fluid containing $6.8 \%$ heat-generating agent A, $7 \%$ heat-generating agent $\mathrm{B}$, and no proppant was pumped into the formation at a pressure of 14-24 MPa and a displacement of $1.5-2 \mathrm{~m}^{3} / \mathrm{min}$ to form and extend fractures.

2. High-pressure pumping sand-carrying liquid 1: $12 \mathrm{~m}^{3}$ in situ heat fracturing fluid containing $6.6 \%$ heat-generating agent $\mathrm{A}, 6.8 \%$ heat-generating agent $\mathrm{B}$, and $0.75 \mathrm{~m}^{3}$ proppant was pumped into the formation at a pressure of 14-24 MPa and a displacement of $1.5-2 \mathrm{~m}^{3} /$ min to further extend the fracture and fill it to form a high-permeability fracture zone.

3. High-pressure pumping sand-carrying liquid 2: The proppant content of $12 \mathrm{~m}^{3}$ in situ heat fracturing fluid containing 6.4\% heat-generating agent $\mathrm{A}$ and $6.6 \%$ heatgenerating agent $B$ was increased to $2.25 \mathrm{~m}^{3}$, and the dose of thickener was increased to $0.33 \%$. At a pressure of 14-24 Mpa and a displacement of $1.5-2 \mathrm{~m}^{3} / \mathrm{min}$, fracturing fluid was pumped into the formation to further extend the fracture and fill it to form a high-permeability fracture zone.

4. High-pressure pumping sand-carrying liquid 3: The proppant content of $12 \mathrm{~m}^{3}$ in situ heat fracturing fluid containing $6.2 \%$ heat-generating agent $\mathrm{A}$ and $6.4 \%$ heatgenerating agent $\mathrm{B}$ was increased to $3 \mathrm{~m}^{3}$, and the dose of thickener was increased to $0.36 \%$. At a pressure of 14-24 MPa and a displacement of $1.5-2 \mathrm{~m}^{3} / \mathrm{min}$, fracturing fluid was pumped into the formation to further extend the fracture and fill it to form a high-permeability fracture zone.

5. High-pressure pumping sand-carrying liquid 4: The proppant content of $12 \mathrm{~m}^{3}$ in situ heat fracturing fluid containing $6 \%$ heat-generating agent $\mathrm{A}$ and $6.2 \%$ heatgenerating agent $\mathrm{B}$ was increased to $4.125 \mathrm{~m}^{3}$, and the dose of thickener was increased to $0.39 \%$. At a pressure of 14-24 MPa and a displacement of $1.5-2 \mathrm{~m}^{3} / \mathrm{min}$, fracturing fluid was pumped into the formation to further extend the fracture and fill it to form a high-permeability fracture zone.

6. High-pressure pumping sand-carrying liquid 5: The proppant content of $12 \mathrm{~m}^{3}$ in situ heat fracturing fluid containing 5.8\% heat-generating agent $\mathrm{A}$ and $6 \%$ heatgenerating agent $\mathrm{B}$ was increased to $7.125 \mathrm{~m}^{3}$, and the dose of thickener was increased to $0.42 \%$. At a pressure of 14-24 MPa and a displacement of $1.5-2 \mathrm{~m}^{3} / \mathrm{min}$, fracturing fluid was pumped into the formation to further extend the fracture and fill it to form a high-permeability fracture zone.

7. High-pressure pumping sand-carrying liquid 6: The proppant content of $12 \mathrm{~m}^{3}$ in situ heat fracturing fluid containing 5.6\% heat-generating agent $\mathrm{A}$ and 5.8\% heatgenerating agent $\mathrm{B}$ was increased to $15 \mathrm{~m}^{3}$, and the dose of thickener was increased to $0.45 \%$. At a pressure of 14-24 MPa and a displacement of $1.5-2 \mathrm{~m}^{3} / \mathrm{min}$, fracturing fluid was pumped into the formation to further extend the fracture and fill it to form a high-permeability fracture zone.

8. High-pressure pumping displacement fluid: $13 \mathrm{~m}^{3}$ in situ heat fracturing fluid containing $5.6 \%$ heat-generating agent $\mathrm{A}, 5.8 \%$ heat-generating agent $\mathrm{B}$, and no proppant was pumped into the formation at a pressure of 14-24 MPa and a displacement of $1.5-2 \mathrm{~m}^{3} / \mathrm{min}$, and all the liquid-carrying sand in the wellbore was pushed into the fracturing to avoid sedimentation on the bottom.

9. The pump was stopped, the instrument truck recorded the oil pipe, and the casing pressure for $10 \mathrm{~min}$.

According to the half-life of the foam tested in the experiment, the well was shut for $13 \mathrm{~h}$. After that, the flowback was carried out, and the flowback liquid was clean and did not contain residue; the flowback rate was $93.73 \%$.

In this construction, a total of $100 \mathrm{~m}^{3}$ of in situ heat fracturing fluid and 20/40 mesh ceramsite were pumped into the formation. The average sand-liquid ratio was $20 \%$, and the highest sand ratio was $25.6 \%$. The well was shut down $13 \mathrm{~h}$ after the injection, and the flowback rate was $93.73 \%$. The viscosity of the flowback fluid was $3.83 \mathrm{mPa}$, and the daily oil production after the fracturing was $2.7 \mathrm{t} / \mathrm{d}$, which was 2.41 times higher than the previous $1.12 \mathrm{t} / \mathrm{d}$.

\section{Conclusion}

The in situ heat/gas clean foam fracturing fluid system has broad applications and development prospects, and is clean, environmentally friendly, and harmless sustainable development on the basis of meeting performance requirements. In this paper, using the $\mathrm{XX}$ reservoir in the $\mathrm{XX}$ oilfield as an example, the main factors affecting the performance of in situ heat fracturing fluid were analyzed and optimized through laboratory experiments. According to the optimized results, a new type of in situ heat/gas clean foam fracturing fluid system was prepared, and its performance was evaluated. Finally, the following conclusions were drawn:

1. The new type of in situ heat/gas clean foam fracturing fluid system has a good heating performance and can effectively reduce the problem of reservoir cold damage.

2. The new type of in situ heat/gas clean foam fracturing fluid has a good expansion and pressure-boosting performance and can generate heat and gas in situ to form a foam-like fracturing fluid. It results in improved system structure viscosity and sand-carrying performance, reduced fluid loss, and increased flowback rate. 
3. Compared with conventional in situ heat fracturing fluid, the new type of in situ heat/gas clean foam fracturing fluid has a good gel-breaking performance. The gel was completely broken at $65{ }^{\circ} \mathrm{C}$ and $4 \mathrm{MPa}$ within $2 \mathrm{~h}$. The viscosity of the gel-breaking liquid was $3.8014 \mathrm{mPa} \mathrm{s}$, and the measured surface tension was $27.70 \mathrm{mN} / \mathrm{m}$.

4. Compared with conventional in situ heat fracturing fluid, the new in situ heat/gas clean foam fracturing fluid has a lower corrosion performance, and the corrosion performance of the system after the formation of a foam-like structure is significantly reduced to a mere $3.9079 \mathrm{~g} /$ $\left(\mathrm{m}^{2} \mathrm{~h}\right)$.

The in situ heat fracturing fluid can increase the reservoir temperature by ensuring the formation of fractures in the reservoir and increasing the permeability, thus avoiding the problem of cold damage and reducing the viscosity of the crude oil. The in situ heat fracturing fluid generates a considerable amount of inert gas while generating heat, thus forming foam-like fracturing fluid. The system can reduce fluid loss, improve the performance of carrying sand, improve the performance of gel breaking and flowback, and effectively improve fracture conductivity. Moreover, it is clean and environmentally friendly. Based on the relevant experimental conclusions and on-site construction applications, the in situ heat fracturing fluid system can effectively avoid the problem of cold damage to the working fluid, improve oil and gas production, and effectively crosslink and carry sand in an acidic environment. The gel-breaking performance of the system is good: The gel-breaking liquid is clear, does not contain residue, is clean and environmentally friendly, and causes minimal damage.

Acknowledgements This work was supported by the National Science and Technology Major Project and National Natural Science Foundation of China Petrochemical Joint Fund Project (U1762107).

Open Access This article is licensed under a Creative Commons Attribution 4.0 International License, which permits use, sharing, adaptation, distribution and reproduction in any medium or format, as long as you give appropriate credit to the original author(s) and the source, provide a link to the Creative Commons licence, and indicate if changes were made. The images or other third party material in this article are included in the article's Creative Commons licence, unless indicated otherwise in a credit line to the material. If material is not included in the article's Creative Commons licence and your intended use is not permitted by statutory regulation or exceeds the permitted use, you will need to obtain permission directly from the copyright holder. To view a copy of this licence, visit http://creativecommons.org/licenses/by/4.0/.

\section{References}

Al-Taq AA, Al-Haji H, Saleem JA (2014) First successful filtercake damage removal treatment utilizing in-situ nitrogen/heat generating system for relatively heavy oil wells. Soc Petrol Eng. https://doi.org/10.2118/170832-MS

Ashton JP, Kirspel LJ, Nguyen HT, Credeur DJ (1989) In-Situ heat system stimulates paraffinic-crude producers in Gulf of Mexico. Soc Petrol Eng. https://doi.org/10.2118/15660-PA

Bayless JH (1997) Oil well stimulation with hydrogen peroxide. Soc Petrol Eng. https://doi.org/10.2118/38348-MS

Bayless JH (1998) Hydrogen peroxide: a new thermal stimulation technique. World Oil 5:29-31

Bayless JH (2000) Hydrogen peroxide applications for the oil industry. World Oil 5:50-53

Blauer RE, Kohlhaas CA (1974) Formation fracturing with foam. Soc Petrol Eng. https://doi.org/10.2118/5003-MS

Bullen RS (1980) Combination foam/fluid fracturing. Petrol Soc Canada. https://doi.org/10.2118/80-03-01

Burgos G, Birch G, Buijse M (2004) Acid fracturing with encapsulated citric acid. Soc Petrol Eng. https://doi.org/10.2118/86484-MS

Collesi JB, Scott TA, McSpadden HW (1987) Surface equipment cleanup utilizing in-situ heat. Soc Petrol Eng. https://doi. org/10.2118/16215-MS

Davies DR, Richardson EA, Antheunis D (1981) Field application of in-situ nitrogen gas generation system. Soc Petrol Eng. https://doi. org/10.2118/9653-MS

Farajzadeh R, Andrianov A, Bruining J, Zitha PLJ (2009) New insights into application of foam for acid diversion. Soc Petrol Eng. https ://doi.org/10.2118/122133-MS

Goenka SK, Singhal J, Kothiyal MD, Parasher A, Tiwari S (2014) Near wellbore asphaltene and wax remediation using in-situ heat generation in both PCP and non-PCP wells: concept, operational challenges and remedial solutions. Soc Petrol Eng. https://doi. org/10.2118/171497-MS

Harris PC (1985) Dynamic fluid loss characteristics of foam fracturing fluids. Soc Petrol Eng. https://doi.org/10.2118/11065-PA

Harris PC, Heath SJ (1996) High-quality foam fracturing fluids. Soc Petrol Eng. https://doi.org/10.2118/35600-MS

Khade SD, Shah SN (2003) New rheological correlations for guar foam fluids. Soc Petrol Eng. https://doi.org/10.2118/80895-MS

Khalil CN, de Franco ZA (1990) Improving matrix acidizing with nitrogen and heat in-situ generation. Soc Petrol Eng. https://doi. org/10.2118/21113-MS

McSpadden HW, Tyler ML, Velasco TT (1986) In-situ heat and paraffin inhibitor combination prove cost effective in NPR \#3. Soc Petrol Eng. https://doi.org/10.2118/15098-MS

Mitchell TI, Donovan SC, Collesi JB, McSpadden HW (1984) Field application of a chemical heat and nitrogen generating system. Soc Petrol Eng. https://doi.org/10.2118/12776-MS

Moorhouse R, Harry DN, Matthews L, Merchant U (1998) Interrelationships between polymer/crosslinker chemistry and performance. Soc Petrol Eng. https://doi.org/10.2118/39531-MS

Rollins JT, Taylor LC (1959) Using heat in combination with solvents to clean up formation flow channels. Soc Petrol Eng. https://doi. org/10.2118/1110-G

Saidu Mohamed A (2013) Thermo chemical in-situ heat generation technique to remove organic solid deposition: effective tool for production enhancement and flow assurance. Offshore Technol Conf. https://doi.org/10.4043/23933-MS

Shaoul JR, Ross MJ, Spitzer WJ, Wheaton SR, Mayland PJ, Singh AP (2009) Hydraulic fracturing with heated fluids brings success in high-pour-point waxy-oil reservoir in India. Soc Petrol Eng. https ://doi.org/10.2118/107338-PA

Tiwari S, Verma SK, Karthik R, Singh AK, Kumar S, Singh M, Kothiyal MD (2014) In-situ heat generation for near wellbore asphaltene and wax remediation. Int Petrol Technol Conf. https://doi. org/10.2523/IPTC-17681-MS

Tuttle RN (1983) High-pour-point and asphaltic crude oils and condensates. Soc Petrol Eng. https://doi.org/10.2118/10004-PA

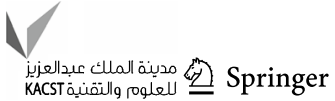


Publisher's Note Springer Nature remains neutral with regard to jurisdictional claims in published maps and institutional affiliations. 